\title{
New records of philometrids (Nematoda: Philometridae) from marine fishes off Japan, including description of Philometra kidakoi sp. n. and Congerinema japonicum gen. et sp. n.
}

\author{
František Moravec $^{1}$, Kazuya Nagasawa ${ }^{2,5}$, Masato Nitta ${ }^{3}$ and Atsushi Tawa ${ }^{4}$ \\ ${ }^{1}$ Institute of Parasitology, Biology Centre of the Czech Academy of Sciences, České Budějovice, Czech Republic; \\ ${ }^{2}$ Graduate School of Integrated Sciences for Life, Hiroshima University, Higashi-Hiroshima, Japan; \\ ${ }^{3}$ Graduate School of Science, Kobe University, 1-1 Rokkodai, Nada, Kobe, Japan; \\ ${ }^{4}$ National Research Institute of Far Seas Fisheries, Japan Fisheries Research and Education Agency, Shimizu, Shizuoka, Japan; \\ ${ }^{5}$ Present address: Aquaparasitology Laboratory, Shimizu, Shizuoka, Japan
}

\begin{abstract}
Occasional examinations of some marine fishes in Japan revealed, in addition to other parasites, the following eight species of philometrid nematodes (Philometridae) (all females only): Philometra kidakoi sp. n. from the ovary of Gymnothorax kidako (Temminck et Schlegel) (Muraenidae); Philometra pinnicola (Yamaguti, 1935) from the operculum of Epinephelus akaara (Temminck et Schlegel) (Serranidae); Philometra sebastisci Yamaguti, 1941 from the ovary of Sebastes cheni Barsukov (Scorpaenidae) (new host); Philometra madai Quiazon, Yoshinaga et Ogawa, 2008 from the ovary of Acanthopagrus schlegelii (Bleeker) (Sparidae) (new host); Philometra isaki Quiazon, Yoshinaga et Ogawa, 2008 from the ovary of Parapristipoma trilineatum (Thunberg) (Haemulidae); Philometra sp. from the ovary of Synanceia verrucosa Bloch et Schneider (Synanceiidae); Congerinema japonicum gen. et sp. n. from the subcutaneous tissue of Conger myriaster (Brevoort) (Congridae); and Clavinema mariae (Layman, 1930) from the operculum of Acentrogobius pflaumii (Bleeker) (Gobiidae). Specimens of all species are described based on light and scanning electron microscopical examinations. Philometra kidakoi sp. n. is the first gonad-infecting philometrid from the Muraenidae. The new monotypic genus Congerinema gen. $\mathrm{n}$. is characterised by the unique net-like cuticular ornamentation on the female body. Clavinema mariae is considered to be a complex of several cryptic species and a need of the discovery of conspecific males is stressed (this also concerns other philometrid species with unknown males). At present, the fauna of philometrid nematodes parasitising marine fishes in Japanese waters is represented by 22 nominal species belonging to four genera.
\end{abstract}

Keywords: Dracunculoidea, Philometra, new taxa, Anguilliformes, Perciformes, Scorpaeniformes, Japanese seas, East Asia

Knowledge of the fauna of philometrid nematodes (Philometridae) parasitising marine fishes in Japanese waters remains fragmentary. To date, a total of 20 nominal species of these parasites, belonging to the genera Clavinema Yamaguti, 1935 (1 species), Philometra Costa, 1845 (17 species) and Philometroides Yamaguti, 1935 (2 species), have been reported from marine representatives of the fish orders Perciformes, Pleuronectiformes, Scorpaeniformes, Siluriformes and Tetraodontiformes from off Japan (Ishii 1931, Yamaguti 1935, 1941, 1961, Machida 1970, Moravec and Nagasawa 1989, Moravec et al. 1998, 2002, 2012a, 2018, Quiazon et al. 2008a,b; see Nagasawa 2008 for the other literature).

During recent studies on parasites of some marine fishes off Japan, philometrid nematodes were collected from eight fish species belonging to the anguilliform families
Congridae and Muraenidae, perciform families Gobiidae, Haemulidae, Serranidae and Sparidae, and to the scorpaeniform families Scorpaenidae and Synanceiidae. Their closer examination showed that they represent one new and six insufficiently known species of Philometra and one new species representing a new genus. These are described below.

\section{MATERIALS AND METHODS}

Fishes were collected in the western North Pacific Ocean and the Seto Inland Sea off Japan. Most of the nematodes obtained were washed in physiological saline and fixed and preserved in $70 \%$ ethanol, but some were directly fixed in 5\% formalin and later transferred into $70 \%$ ethanol. For light microscopical (LM) examination, the nematodes were cleared in glycerine. Drawings were made with the aid of a Zeiss drawing attachment. Specimens used for scanning electron microscopy (SEM) were postfixed in 


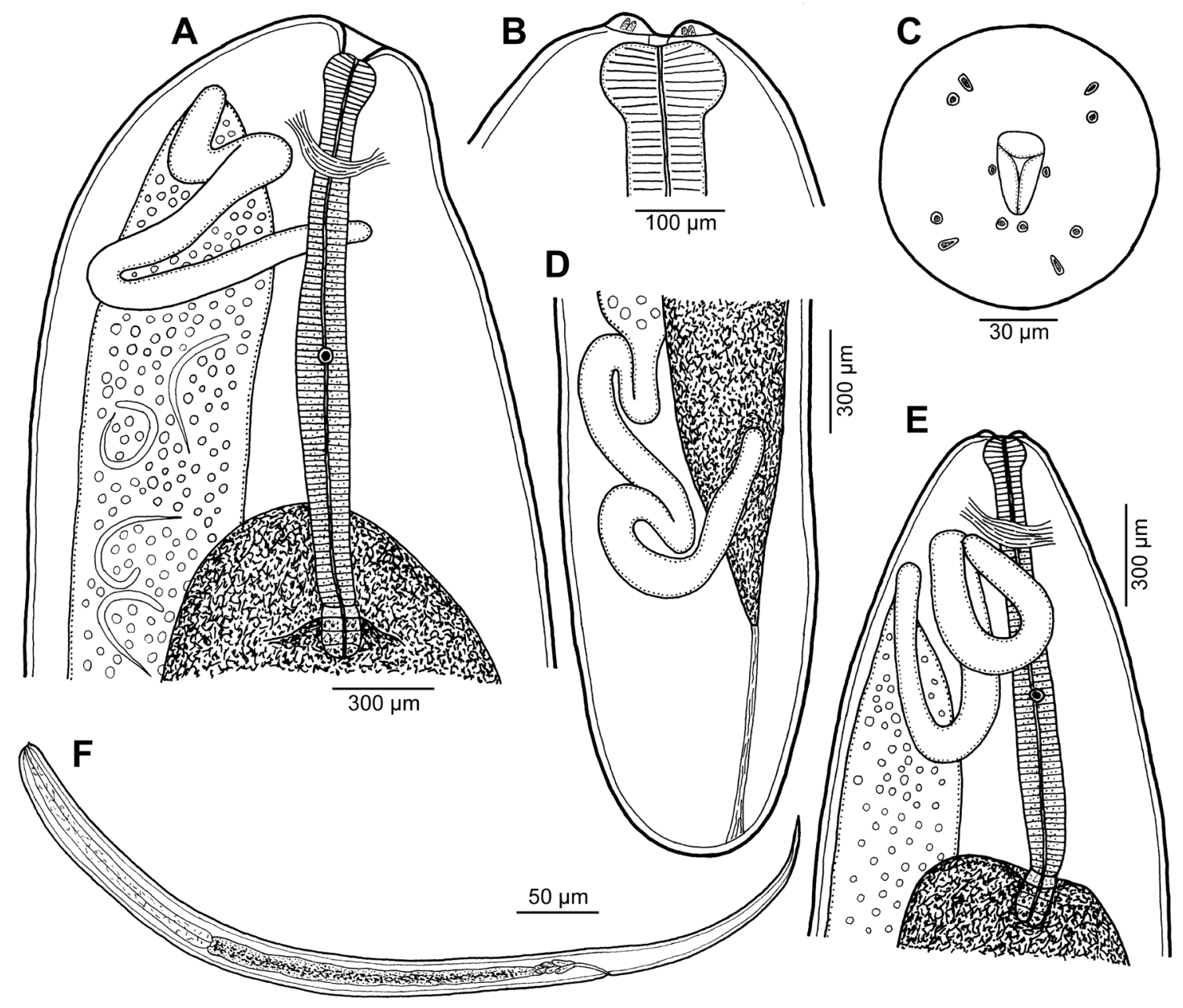

Fig. 1. Philometra kidakoi sp. n. from Gymnothorax kidako (Temminck et Schlegel), females. A - anterior end of gravid female, lateral view; B, C - cephalic end of subgravid female, lateral and apical views, respectively; D - posterior end of subgravid female, lateral view; $\mathbf{E}$ - anterior end of subgravid female, lateral view; $\mathbf{F}$ - larva from uterus.

$1 \%$ osmium tetroxide (in phosphate buffer), dehydrated through a graded acetone series, critical-point-dried and sputter-coated with gold; they were examined using a JEOL JSM-7401F scanning electron microscope at an accelerating voltage of $4 \mathrm{kV}$ (GB low mode). All measurements are in micrometres unless otherwise indicated. The type and voucher specimens have been deposited in the Helminthological Collection of the Institute of Parasitology, Biology Centre of the Czech Academy of Sciences, České Budějovice, Czech Republic (IPCAS). The fish nomenclature adopted follows FishBase (Froese and Pauly 2019).

\section{RESULTS}

\section{Philometridae Baylis et Daubney, 1926}

\section{Philometra kidakoi sp. n.}

Figs. 1-3

ZooBank number for species:

urn:Isid:zoobank.org:act:40265A40-F521-4CF4-A3EF-30418EC1C492

Subgravid female (1 specimen, holotype). Body of fixed specimen light brown, filiform, $135 \mathrm{~mm}$ long, maximum width $1.40 \mathrm{~mm}$; width of cephalic end 299, width of caudal end 680; posterior part of body narrower than anterior part. Cuticle smooth. Maximum width/length ratio of body $1: 96$. Anterior end of body rounded, provided with 4 forwardly protruding dome-shaped projections 18 high (Fig. 1B,E). Oral aperture oval, dorsoventrally elongate, surrounded by 12 small cephalic papillae arranged in 2 circles; external circle formed by 4 submedian pairs of papillae, each pair being located on cephalic projection; internal circle consists of 2 submedian subventral and 2 lateral single papillae (submedian subdorsal papillae appearing to be absent); amphids indistinct (Figs. 1C, 2A-C). Bottom of mouth formed by surfaces of 3 lobular oesophageal sectors. Oesophagus narrow, somewhat swollen near mouth to form bulb 90 long and 156 wide, not distinctly separated from posterior cylindrical part of oesophagus (Fig. 1B,E). Oesophagus $1.44 \mathrm{~mm}$ long, representing $1 \%$ of body length; maximum width of its cylindrical part 136 . Oesophageal gland moderately developed, extending from level of nerve ring to end of oesophagus, with poorly visible cell nucleus at its middle. Nerve ring 354 from anterior end of body. Ventriculus small, 30 long, 93 wide. Oesophagus opens into intestine through distinct valve. Intestine broad, dark-brown, ending blindly; its posterior end atro- 

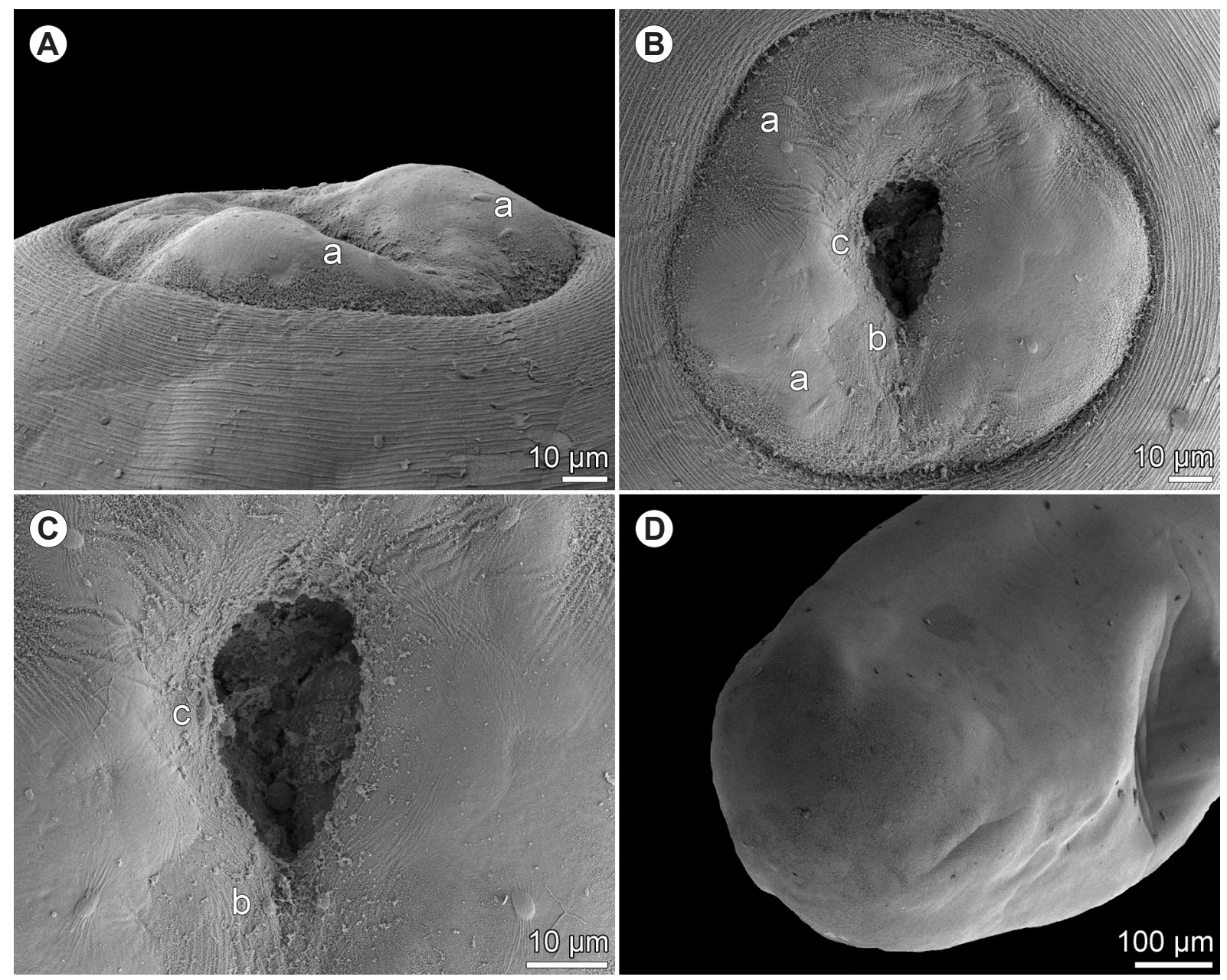

Fig. 2. Philometra kidakoi sp. n. from Gymnothorax kidako (Temminck et Schlegel), scanning electron micrographs of subgravid female. A, B - cephalic end, sublateral and apical views, respectively; $\mathbf{C}$ - region of oral aperture, apical view; D - caudal end, subapical view. Abbreviations: a - submedian pair of cephalic papillae of outer circle; $\mathrm{b}$ - submedian cephalic papilla of inner circle; $\mathrm{c}$ - lateral cephalic papilla of inner circle.

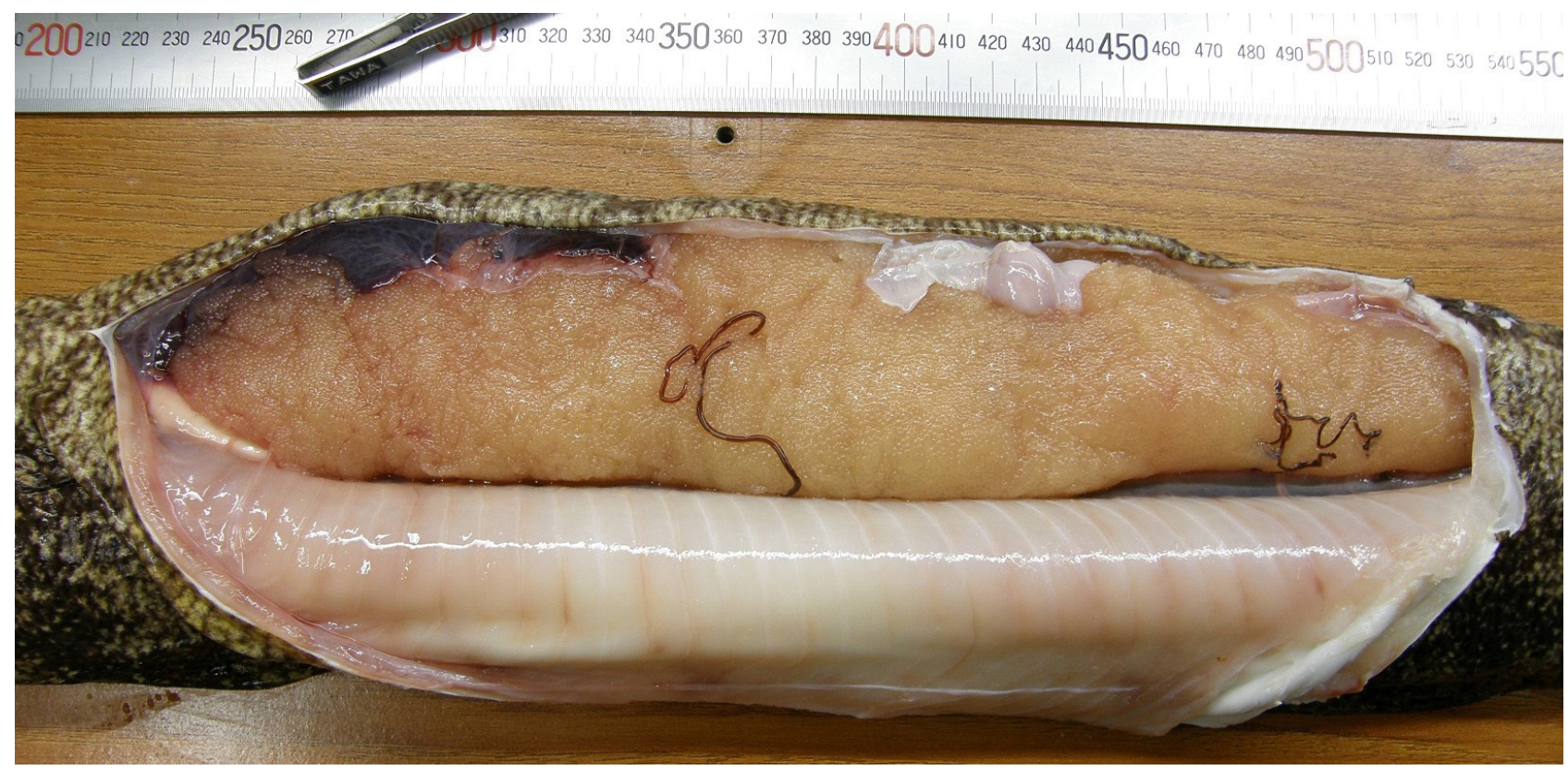

Fig. 3. Two females of Philometra kidakoi sp. n. on the ovary of the infected kidako moray, Gymnothorax kidako (Temminck et Schlegel). 
phied, forming ligament 680 long, attached ventrally to body wall near posterior extremity (Fig. 1D). Posterior end of body rounded, without any caudal projections (Fig. 1D). Two ovaries rather short, reflected, situated near anterior and posterior ends of body (Fig. 1D,E). Uterus containing many eggs extends anteriorly to short distance posterior to nerve ring (Fig. 1E).

Gravid female (1 specimen without posterior end, paratype). Length of body fragment $82 \mathrm{~mm}$, maximum width $1.43 \mathrm{~mm}$. Cuticle smooth. Mouth markedly depressed, cephalic papillae indistinct in lateral view; width of cephalic end 544 (Fig. 1A). Oesophagus narrow, somewhat swollen near mouth to form bulb 120 long and 180 wide, not distinctly separated from posterior cylindrical part of oesophagus. Oesophagus $1.77 \mathrm{~mm}$ long, maximum width of its cylindrical part 150 . Oesophageal gland moderately developed; its cell nucleus not well visible, 993 from anterior extremity (Fig. 1A). Nerve ring 408 from anterior end of body. Uterus containing numerous eggs and larvae extends anteriorly to level of nerve ring (Fig. 1A). Larvae $(\mathrm{n}=5)$ 552-600 long and 18-20 wide, their oesophagus 138-156 long (24-26\% of body length) and slender, sharply pointed tail 165-180 long (29-30\% of body length) (Fig. 1F).

Male. Not known.

Type host: Kidako moray, Gymnothorax kidako (Temminck et Schlegel) (Muraenidae, Anguilliformes).

Site of infection: Ovary.

Type locality: Western North Pacific Ocean off Akamizu, Nobeoka City, Miyazaki Prefecture, Kyushu, Japan (collected on 25 July 2007)

Prevalence and intensity: 1 fish infected/1 fish examined; 2 nematodes.

Deposition of type specimens: IPCAS N-1194 (holotype mounted on SEM stub, paratype in vial).

Etymology: The specific name kidakoi is the genitive form of the species name of the host.

Remarks. Gonad-infecting species of Philometra exhibit a rather high degree of host specificity, so that it is possible to deal with them within the family of their fish hosts (Moravec and de Buron 2013, Moravec et al. 2014, 2016b). Regarding the family Muraenidae, Linton (1907) was the first to report Ichthyonema (= Philometra) sp. in Gymnothorax moringa (Cuvier) in the northeastern Atlantic Ocean from off Bermuda (see also Moravec 2006); he found just one small specimen (apparently a young female), but he did not mention the site of infection in the host. Nevertheless, it is highly probable that his nematode was conspecific with Philometra gymnothoracis Moravec et de Buron, 2009, a species later described from two gravid females collected from the body cavity of the same host species (G. moringa) off the Atlantic coast of South Carolina, USA (Moravec and de Buron 2009). To date, this is the only nominal species of Philometra reported from moray eels (Muraenidae).

The female morphology of $P$. kidakoi sp. n. is rather similar to that of $P$. gymnothoracis, but, in contrast, the new species has no caudal projections ( $v s$ pair of small caudal projections present). In addition, the oesophagus of the gravid female of $P$. kidakoi is somewhat shorter $(1.77 \mathrm{~mm}$ vs $2.18-2.61 \mathrm{~mm})$ and its anterior bulb is smaller $(120 \times$ $180 \mu \mathrm{m} v s$ 163-204 × 231-255 $\mu \mathrm{m})$. Moreover, the hosts of both species have different areas of distribution (G. kidako in the western North Pacific Ocean vs G. moringa in the Atlantic Ocean). Therefore, the specimens from G. kidako are considered to represent a new species of Philometra.

Whereas $P$. gymnothoracis was reported from the host's body cavity, the females of $P$. kidakoi sp. n. were found on the surface of the ovary, partly penetrating into its outer layer, as visible in Fig. 3. Typical gonad-infecting species of Philometra have their gravid females inside the fish ovary.

Philometra pinnicola (Yamaguti, 1935) Yamaguti, 1941

Figs. 4, 5

\section{Syn.: Sanguinofilaria pinnicola Yamaguti, 1935}

Gravid female (1 specimen). Body of fixed specimen whitish, elongate, $32 \mathrm{~mm}$ long, maximum width 991, somewhat tapering to both ends; width of cephalic end 163 , width of caudal end 82 . Cuticle slightly transversely striated. Maximum width/length ratio of body $1: 35$. Anterior end of body rounded (Fig. 4A). Oral aperture oval, dorsoventrally elongate, surrounded by 14 small cephalic papillae arranged in 2 circles; external circle formed by 4 submedian pairs of papillae; internal circle consists of submedian and 2 lateral single papillae; amphids indistinct (Figs. 4C, 5A). Bottom of mouth formed by surfaces of 3 lobular oesophageal sectors. Oesophagus narrow, somewhat swollen near mouth to form anterior inflation 150 long and 122 wide, not distinctly separated from posterior cylindrical part of oesophagus (Fig. 4A). Oesophagus $1.65 \mathrm{~mm}$ long, representing $5 \%$ of body length. Oesophageal gland extending from level of nerve ring to end of oesophagus, with poorly visible cell nucleus at its middle. Nerve ring 204 from anterior end of body. Small ventriculus present. Oesophagus opens into intestine through distinct valve. Intestine narrow, light-coloured, ending blindly; its posterior end atrophied, forming ligament $2.80 \mathrm{~mm}$ long, attached ventrally to body wall near posterior extremity (Fig. 4B, E). Posterior end of body conical with rounded tip bearing pair of minute, hardly visible caudal double projections (Figs. 4B,E, 5B-D). Ovaries not visible, being overlapped by mass of larvae. Most space of body filled with uterus extending from level of nerve ring to nearly end of body, containing numerous larvae (Fig. 4A,B). Larvae $(n=5)$ 408-441 long, maximum width 15-18, with sharply pointed tail; length of their oesophagus 90-102 (20-23\% of body length), of tail $120-126$ (27-31\% of body length).

Male. Not known.

Host: Hong Kong grouper, Epinephelus akaara (Temminck et Schlegel) (Serranidae, Perciformes).

Site of infection: Under the skin of the operculum.

Locality: Seto Inland Sea off Imabari City, Ehime Prefecture, Shikoku, Japan (collected on 10 November 2017).

Prevalence and intensity: 1 fish infected/1 fish examined; 1 nematode.

Deposition of voucher specimen: IPCAS N-1196. 

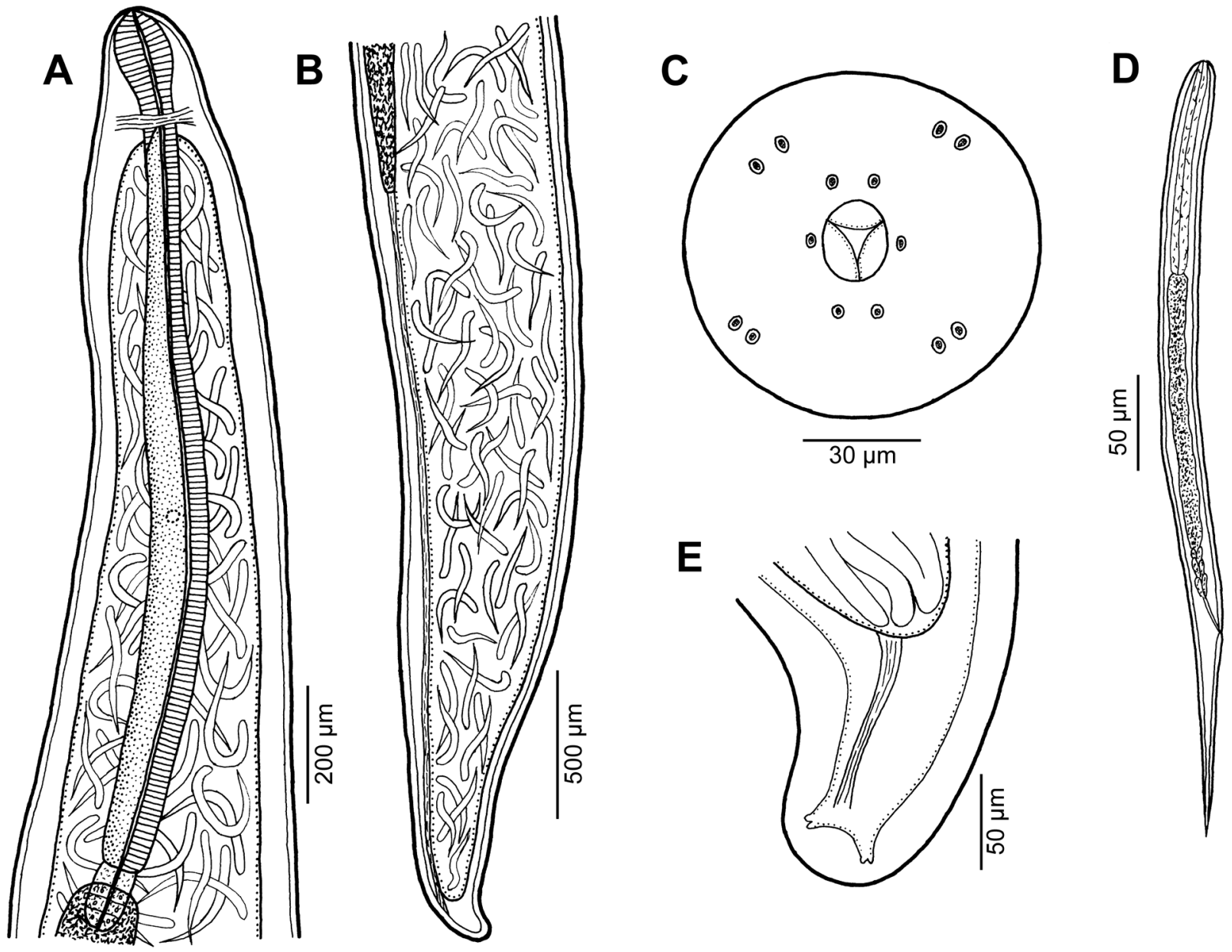

Fig. 4. Philometra pinnicola (Yamaguti, 1935) from Epinephelus akaara (Temminck et Schlegel), gravid female. A, B - anterior and posterior ends of body, respectively, lateral views; C - cephalic end, apical view; D - larva from uterus, lateral view; $\mathbf{E}-$ caudal end, dorsoventral view.

Remarks. By the morphology and measurements, the present specimen (gravid female) resembles $P$. pinnicola (Yamaguti, 1935), a species described by Yamaguti (1935) as Sanguinofilaria pinnicola solely from females in the fins of E. akaara in the Seto Inland Sea (reported as the Inland Sea), Japan. Later Yamaguti (1941) recorded females of this species from the fins of the same host species in the same locality; he considered Sanguinofilaria Yamaguti, 1935 to be a junior synonym of Philometra and transferred S. pinnicola to the latter genus. The species has not been recorded since.

Description of $P$. pinnicola by Yamaguti $(1935,1941)$ is very brief and incomplete (see also Moravec 2006) and some reported measurements somewhat differ from those found in the present specimen (e.g., the length of the oesophagus $1.00-1.35 \mathrm{~mm} v s 1.65 \mathrm{~mm}$; the length of larvae $320-370 \mu \mathrm{m}$ vs $408-441 \mu \mathrm{m})$. However, these differences are negligible and considering that both forms are subcutaneous parasites of the same host species (E. akaara) in the same region (Japan), undoubtedly they belong to one and the same species. Some species of Philometra parasitising subcutaneous tissues, e.g., Philometra rischta Skrjabin, 1923, are known to be located both in the host's opercula and fins (Skrjabin 1923, Levashov 1929, Molnár 1966, Moravec 2013).
In having a conspicuously narrowed, conical posterior end of the body and a markedly long ligament, the present specimen is similar to the gravid females of Philometra epinepheli Dewi et Palm, 2013, as redescribed by Moravec and Diggles (2014), differing from them mainly in poorly developed, indistinct caudal projections (vs caudal projections conspicuous). Philometra epinepheli is a parasite of the inner side of the opercula of Epinephelus coioides (Hamilton) from off Indonesia and northern Australia (Dewi and Palm 2013, Moravec and Diggles 2014).

By the conspicuously narrowed female posterior end, $P$. pinnicola also resembles Philometra deburonae Moravec, Bakenhaster et Adams, 2016, a species described from the subcutaneous tissue of the inner operculum of Mycteroperca venenosa (Linnaeus) (Serranidae) in the Gulf of Mexico (Moravec et al. 2016a), but the latter nematode differs in possessing the oesophageal gland extending anteriorly beyond the nerve ring and in having conspicuous papilla-like caudal projections.

Cephalic papillae and minute caudal projections in $P$. pinnicola are reported here for the first time. This is the first record of this nematode since it was reported by Yamaguti (1941). 

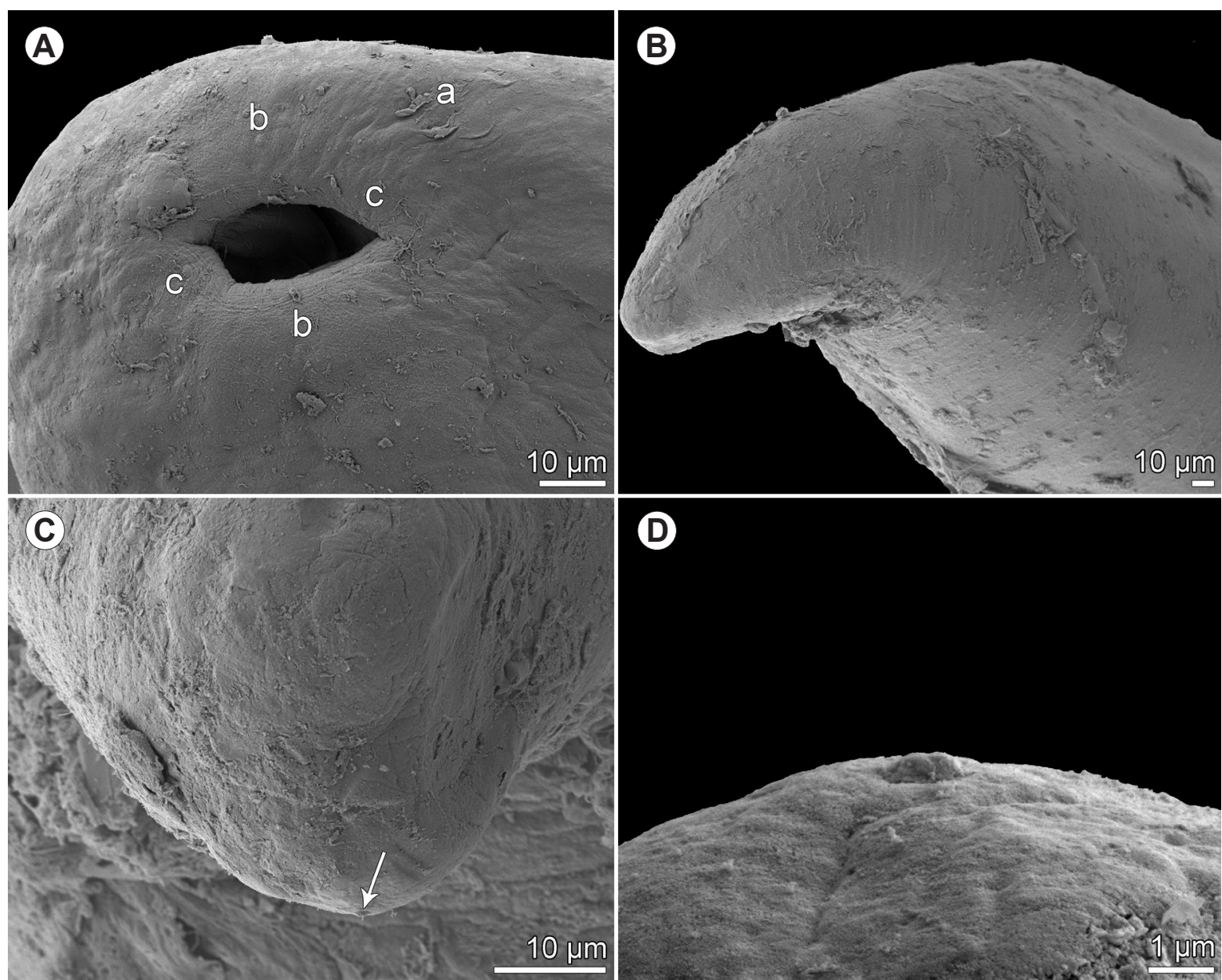

Fig. 5. Philometra pinnicola (Yamaguti, 1935) from Epinephelus akaara (Temminck et Schlegel), scanning electron micrographs of gravid female. A - cephalic end, subapical view; B - caudal end, lateral view; $\mathbf{C}$ - caudal end, subapical view (arrow indicates caudal double projection); D - caudal double projection, lateral view. Abbreviations: a - submedian pair of cephalic papillae of outer circle; $\mathrm{b}$ - submedian cephalic papilla of inner circle; $\mathrm{c}$ - lateral cephalic papilla of inner circle.

Philometra sebastisci Yamaguti, 1941

Subgravid females (3 specimens). Body of fixed specimens dark-brown to nearly black, almost non-transparent after clearing in glycerine, elongate, with anterior part somewhat broader than posterior one. Anterior end somewhat narrowed, rounded; width of cephalic end 177 272 (Fig. 6A). Length of body 55-115 mm, maximum width 1.33-1.97 mm. Cuticle smooth. Maximum width/ length ratio of body $1: 41-64$. Cephalic papillae very small, almost indistinct in lateral view; papillae arranged in 2 circles: 4 submedian pairs of papillae of outer circle and 6 single papillae (4 submedian and 2 lateral) of inner circle (Figs. 6C, 7A). Oesophagus swollen near mouth to form distinct muscular bulb 177-204 long and 190-218 wide. Overall length of oesophagus including anterior bulb $1.31-1.40 \mathrm{~mm}$, representing $1.2-2.5 \%$ of body length, maximum width of its cylindrical part 150-153. Oesophageal gland poorly developed; its cell nucleus not readily visible, 830 from anterior extremity in specimen $105 \mathrm{~mm}$ long (Fig. 6A). Very small ventriculus present. Nerve ring 190258 from anterior end of body. Intestine nerly black, very broad almost throughout all body length. Posterior end of intestine atrophied, attached subterminally to ventral body wall by short ligament (Fig. 6B). Vagina and vulva absent. Ovaries comparatively thick, reflected, situated near anterior and posterior ends of body. Uterus occupying major part of body, extending anteriorly to oesophageal bulb and posteriorly almost to posterior extremity, being filled with large number of eggs; some eggs in 2 larger specimens already with developing larvae (Fig. 6D), but no free, hatched larvae present. Posterior end of body rounded, without any caudal projections (Figs. 6B, 7B).

Male: Not known.

Host: Black rockfish, Sebastes cheni Barsukov (Scorpaenidae, Scorpaeniformes).

Site of infection: Ovary.

Locality: Seto Inland Sea off Nagahama, Kure City, Hiroshima Prefecture, Honshu, Japan (collected on 30 April 2013).

Prevalence and intensity: 1 fish infected/1 fish examined; 2 nematodes.

Deposition of voucher specimens: IPCAS N-701.

Remarks. By the general morphology, especially the markedly dark-coloured body, a poorly-developed dorsal oesophageal gland, a well-developed anterior oesophageal bulb and the body up to about $100 \mathrm{~mm}$ long, the present 

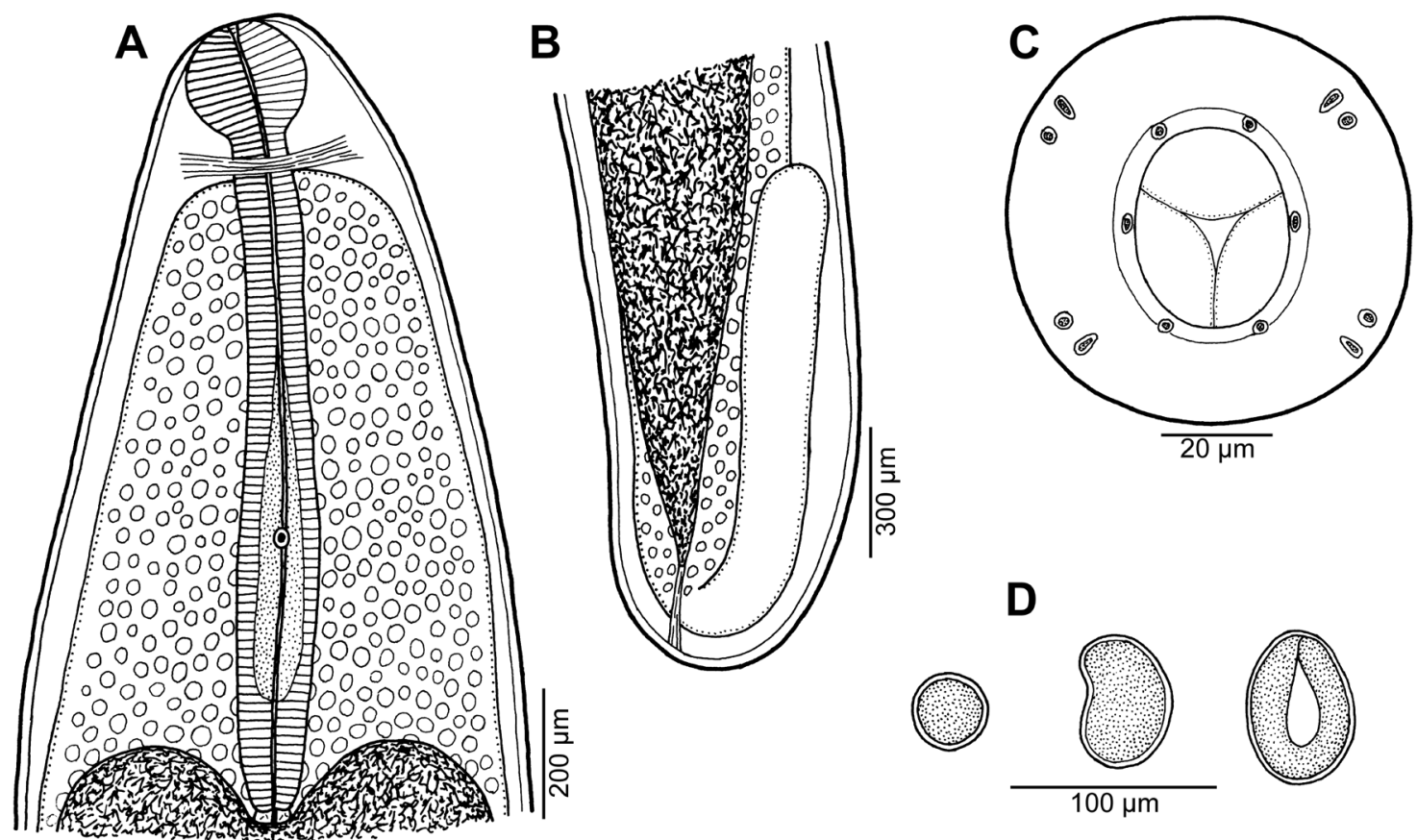

Fig. 6. Philometra sebastisci Yamaguti, 1941 from Sebastes cheni Barsukov, subgravid female. A, B - anterior and posterior ends of body, respectively, lateral views; $\mathbf{C}$ - cephalic end, apical view; $\mathbf{D}$ - eggs at different developmental stages.
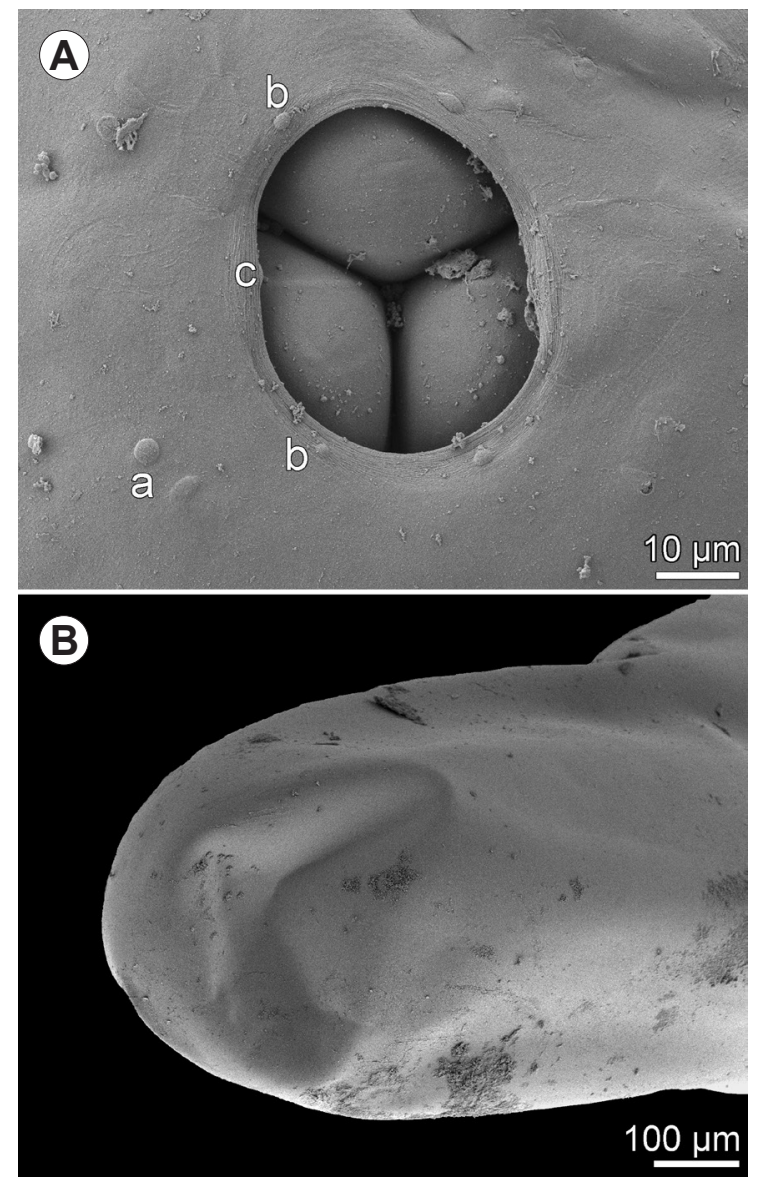

Fig. 7. Philometra sebastisci Yamaguti, 1941 from Sebastes cheni Barsukov, scanning electron micrographs of subgravid female. A - cephalic end, apical view; B - caudal end, lateral view. Abbreviations: a - submedian pair of cephalic papillae of outer circle; $\mathrm{b}$ - submedian cephalic papilla of inner circle; $\mathrm{c}$ - lateral cephalic papilla of inner circle. specimens are very similar to P. sebastisci Yamaguti, 1941, as redescribed by Moravec et al. (1998), differing from it only in the absence of minute, hardly visible caudal projections. However, this difference is negligible, because the caudal projections were described as indistinct in gravid females of $P$. sebastisci and apparently these may be absent in conspecific subgravid females.

Since also the site of infection in the host (ovary) and the geographical region (Japan) of both these forms are identical and their hosts belong to the same fish family Sebastidae, the present specimens are considered to belong to P. sebastisci. Nevertheless, the authors are aware of the fact that the males of $P$. sebastisci from both host species recorded remain unknown; their discovery might confirm the conspecificity of both forms.

Philometra sebastisci was originally described by Yamaguti (1941) from the ovary of Sebastiscus marmoratus (Cuvier) (Sebastidae, Scorpaeniformes) from the East China Sea and the west coast of Kyushu from Japan; later it was redescribed by Moravec et al. (1998) based on specimens collected from the ovary of the same host species from off the west coast of Shikoku Island, Japan (North Pacific Ocean). Sebastes cheni represents a new host for this nematode.

To date, $P$. sebastisci is the only known gonad-infecting species of Philometra parasitising hosts of the scorpaeniform family Sebastidae. Earlier reports on P. sciaenae Yamaguti, 1941 in Sebastes schlegelii Hilgendorf and $P$. pellucida (Jägerskiöld, 1893) in Sebastiscus marmoratus (see Moravec 2006) were based on evident misidentifications. The only other nominal species of Philometra parasitising fishes of the Sebastidae is P. sebastodis Yamaguti, 1941 from the pectoral fins of Sebastes joyneri Günther in Suruga Bay, Honshu, Japan (Yamaguti 1941), differing from 

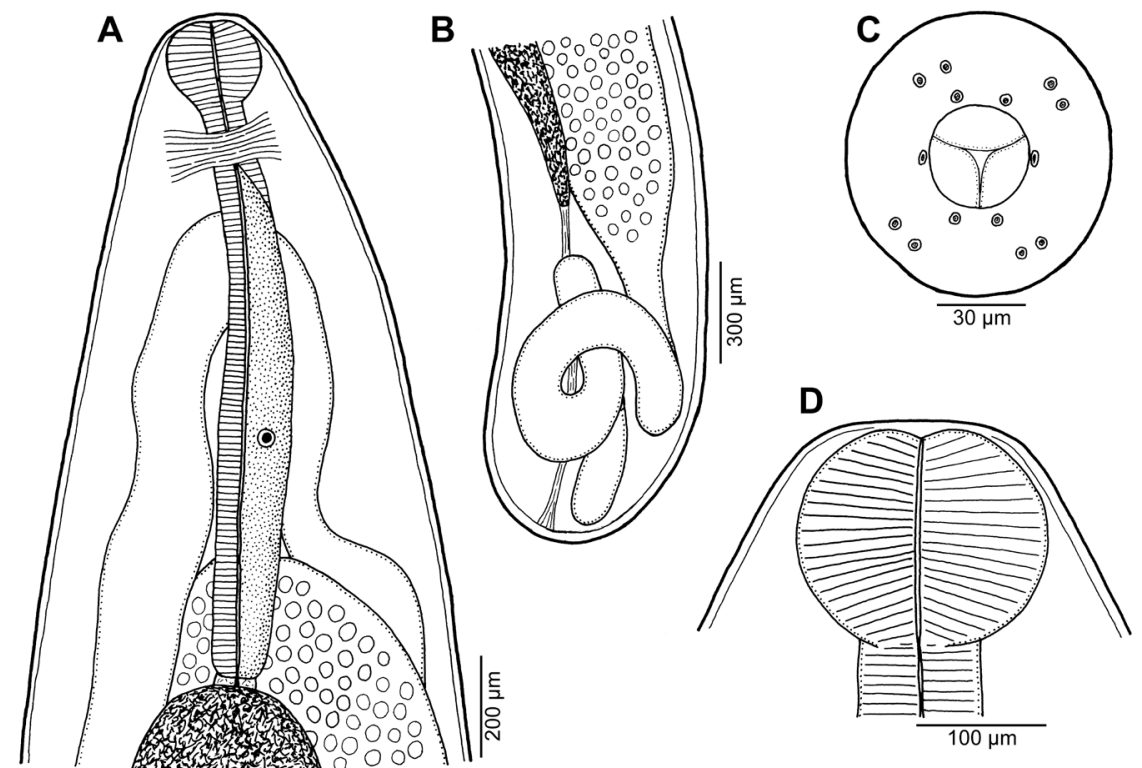

Fig. 8. Philometra madai Quiazon, Yoshinaga et Ogawa, 2008 from Acanthopagrus schlegelii (Bleeker), subgravid female. A, B - anterior and posterior ends of body, respectively, lateral views; $\mathbf{C}$ - cephalic end, apical view; $\mathbf{D}$ - anterior bulbous inflation of oesophagus.
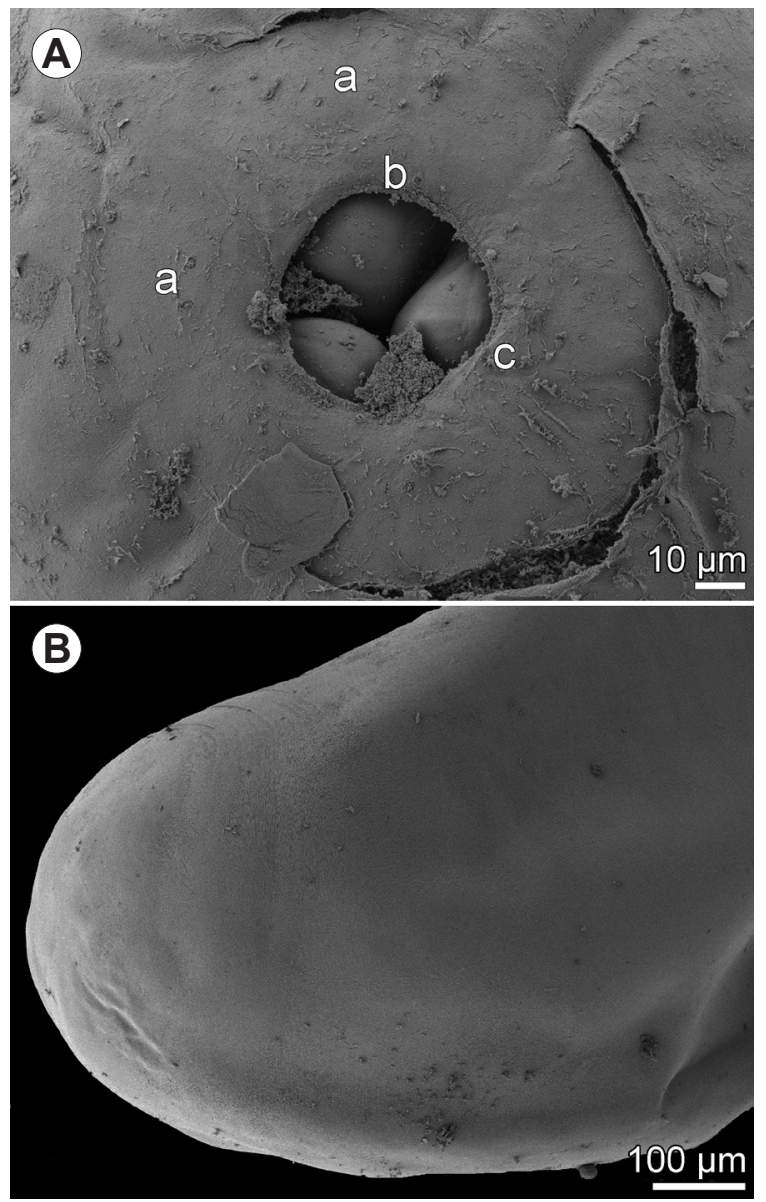

Fig. 9. Philometra madai Quiazon, Yoshinaga et Ogawa, 2008 from Acanthopagrus schlegelii (Bleeker), scanning electron micrographs of subgravid female. A - cephalic end, apical view; B - caudal end, lateral view. Abbreviations: a - submedian pair of cephalic papillae of outer circle; $b$ - submedian cephalic papilla of inner circle; $\mathrm{c}$ - lateral cephalic papilla of inner circle.
P. sebastisci by considerably smaller body measurements. In addition, Ko and Chan (2002) described the male and small mature females of Philometra sp. from the abdominal cavity of S. marmoratus in the South China Sea off Hong Kong; it cannot be excluded that these belonged to P. sebastisci.

\section{Philometra madai Quiazon, Yoshinaga et Ogawa, 2008}

Figs. 8, 9

Subgravid female (4 specimens). Body of fixed specimens yellow-brown, elongate, with anterior part somewhat broader than posterior one. Anterior end somewhat narrowed, rounded; width of cephalic end 245-258 (Fig. 8A). Length of body $56-78 \mathrm{~mm}$, maximum width $1.35-1.83$ $\mathrm{mm}$. Cuticle smooth. Maximum width/length ratio of body 1 : 42-48. Cephalic papillae very small, almost indistinct in lateral view; papillae arranged in 2 circles: 4 submedian pairs of papillae of outer circle and 6 single papillae (4 submedian and 2 lateral) of inner circle (Figs. 8C, 9A). Oesophagus swollen near mouth to form distinct bulb 150-190 long and 163-218 wide. Overall length of oesophagus including anterior bulb $1.27-1.47 \mathrm{~mm}$, representing $2.1-2.3 \%$ of body length, maximum width of its cylindrical part 150-163. Oesophageal gland well developed, extending from level of nerve ring to posterior end of oesophagus, containing large cell nucleus at its middle (Fig. 8A). Very small ventriculus present. Nerve ring 204-313 from anterior end of body. Intestine wide, its posterior end atrophied, attached subterminally to ventral body wall by short ligament (Fig. 8B). Vagina and vulva absent. Ovaries comparatively thick, reflected, situated near anterior and posterior ends of body (Fig. 8A, B). Uterus extending anteriorly to base of oesophagus and posteriorly to short distace anterior to posterior extremity, being filled with large number of eggs (Fig. 8A,B). Posterior end of body rounded, without any caudal projections (Figs. 8B, 9B). 
Host: Blackhead seabream, Acanthopagrus schlegelii (Bleeker) (Sparidae, Perciformes).

Site of infection: Ovary.

Locality: Seto Inland Sea (Hiroshima Bay) off Hiroshima City, Hiroshima Prefecture, Honshu, Japan (collected on 10 January 2006).

Prevalence and intensity: 1 fish infected/1 fish examined; 4 nematodes.

Deposition of voucher specimens: IPCAS N-889.

Remarks. Only two nominal gonad-infecting species of Philometra are known from fishes of the family Sparidae: P. filiformis (Stossich, 1896) from Pagellus erythrinus (Linnaeus) in the seas of the Mediterranean region (Stossich 1896, Moravec and Genc 2004, Moravec et al. 2008a, 2017, Marino et al. 2016) and P. madai from $\mathrm{Pa}$ grus major (Temminck et Schlegel) in the Seto Inland Sea, Japan (Quiazon et al. 2008a). Previous reports on $P$. lateolabracis (Yamaguti, 1935) in Pagrus auratus (Forster) and P. major, and P. salgadoi Vidal-Martinez, Aguirre-Macedo et Moravec, 1995 in the gonads of Boops boops (Linnaeus) (see Moravec 2006) were evidently based on misidentifications (Moravec et al. 2008a, Quiazon et al. 2008a).

The general morphology of the present specimens is in agreement with the description of $P$. madai and, therefore, these are assigned to this species. It should be noted again that this identification can be confirmed when also male specimens from the gonads of $A$. schlegelii are available to study. In contrast to $P$. madai, the oesophagus of gravid and subgravid females of $P$. filiformis has no anterior bulbous inflation. The finding of $P$. madai in A. schlegelii represents a new host record.

In addition to the above-mentioned gonad-infecting species of Philometra, three other philometrids are known as parasites of other organs in sparid fishes: Philometra spari Yamaguti, 1961 from the swimbladder of A. schlegelii in Japan (Yamaguti 1961); P. obladae Moravec, Gaglio, Panebianco et Giannetto, 2008 from the body cavity of Oblada melanura (Linnaeus) in the Tyrrhenian Sea off Sicily, Italy (Moravec et al. 2008a); and Philometroides acanthopagri Moravec, Jassim et Al-Salim, 2012 from the musculature of Acanthopagrus latus (Houttuyn) in the Arabian Gulf off Iraq (Moravec et al. 2012b).

Although $P$. spari was described from the same host species (A. schlegelii) and the same region (off Japan) as the present specimens, it differs from $P$. madai in the shape of the female caudal end (truncated at tip vs tip rounded) and the presence ( $v s$ absence) of caudal papilla-like projections, in addition to a different location in the host (swimbladder $v s$ ovary).

In Japan, before $P$. madai was originally described by Quiazon et al. (2008a), the species had been studied, as $P$. spari (see Sakaguchi and Matsusato 1978), P. lateolabracis (see Sakaguchi et al. 1987a,b) or Philometra sp. (see Nakajima and Egusa 1979), for its morphology and ecology in cultured and wild $P$. major.

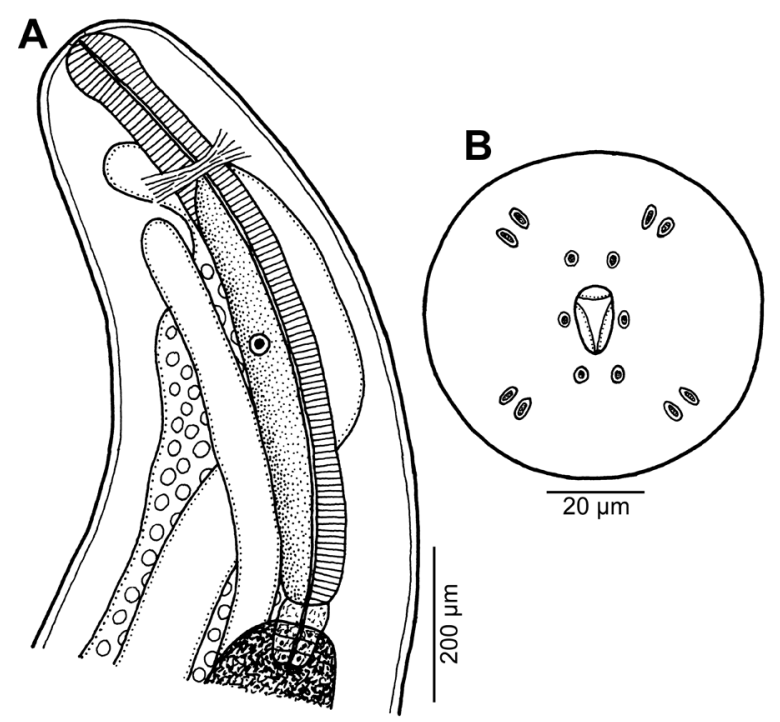

Fig. 10. Philometra isaki Quiazon, Yoshinaga et Ogawa, 2008 from Parapristipoma trilineatum (Thunberg), subgravid female. A - anterior end of body, lateral view; $\mathbf{B}$ - cephalic end, apical view.

\section{Philometra isaki Quiazon, Yoshinaga et Ogawa, 2008}

Figs. 10, 11

Subgravid female ( 2 specimens without posterior ends). Body of fixed specimens whitish. Length of body fragments without posterior ends $52-58 \mathrm{~mm}$, maximum width 680-775. Anterior end somewhat narrowed, rounded; width of cephalic end 204-245 (Fig. 10A). Cuticle smooth. Cephalic papillae very small, almost indistinct in lateral view; papillae arranged in 2 circles: 4 submedian pairs of papillae of outer circle and 6 single papillae (4 submedian and 2 lateral) of inner circle (Figs. 10B, 11A,B). Anterior oesophageal inflation moderately developed, 75-96 long and 90-102 wide. Overall length of oesophagus including anterior inflation 762-884, maximum width of its cylindrical part 82-95. Oesophageal gland well developed, extending from level of nerve ring to posterior end of oesophagus, containing large cell nucleus situated 503 from anterior extremity (Fig. 10A). Ventriculus small, 24-36 long, 78-87 wide. Nerve ring 258 from anterior end of body. Intestine light-coloured. Vagina and vulva absent. Uterus extending anteriorly to level of nerve ring, being filled with many eggs (Fig. 10A).

Host: Chicken grunt, Parapristipoma trilineatum (Thunberg) (Haemulidae, Perciformes).

Site of infection: Ovary.

Locality: Western North Pacific Ocean (Bungo Channel) off Kamiura, Saeki City, Oita Prefecture, Kyushu, Japan (collected on 21 July 2005).

Prevalence and intensity: 1 fish infected/1 fish examined; 3 nematodes.

Deposition of voucher specimens: IPCAS N-888.

Remarks. The present material included three incomplete females, two subgravid and one nongravid specimens. The morphology of subgravid specimens is in agree- 

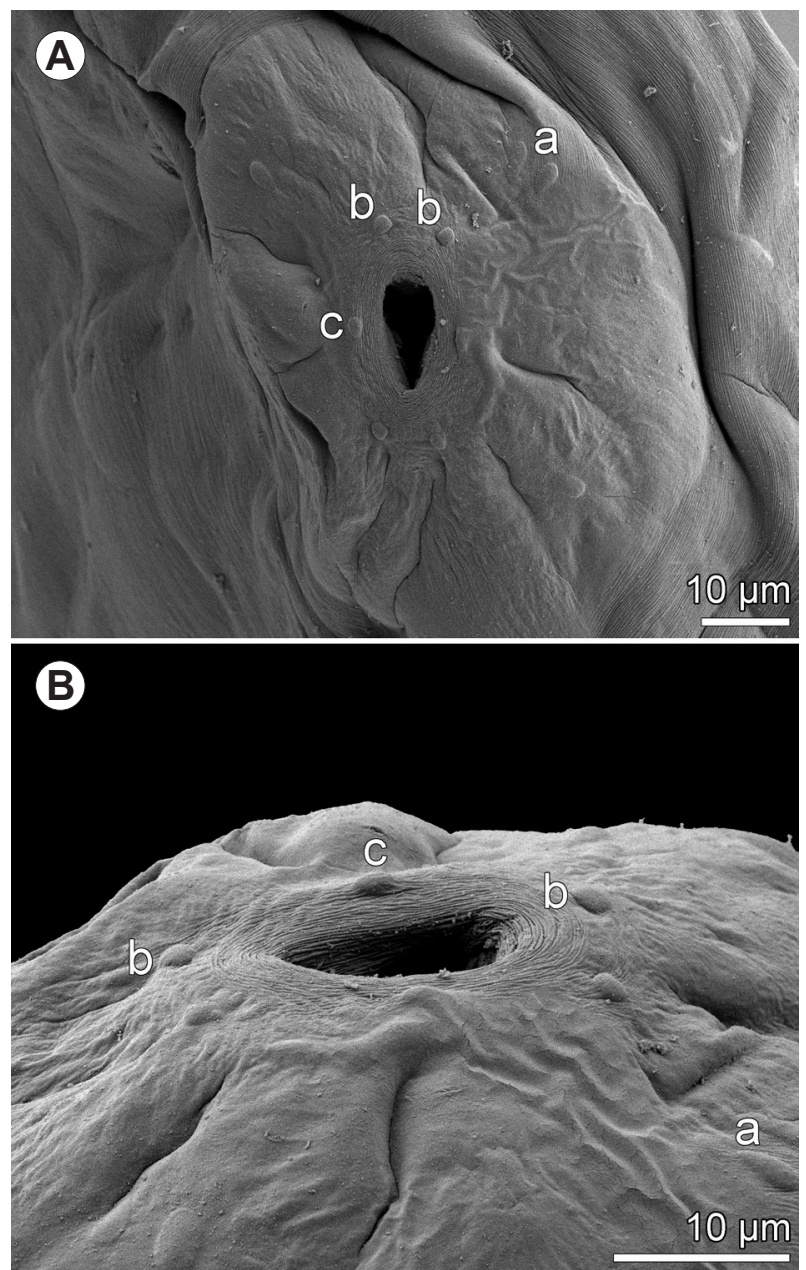

Fig. 11. Philometra isaki Quiazon, Yoshinaga et Ogawa, 2008 from Parapristipoma trilineatum (Thunberg), scanning electron micrographs of subgravid female. A, B - cephalic end, apical and sublateral views, respectively. Abbreviations: a - submedian pair of cephalic papillae of outer circle; $b$ - submedian cephalic papilla of inner circle; $c$ - lateral cephalic papilla of inner circle.

ment with the description of $P$. isaki and since also the host species and the location in the host's body are identical, there is no doubt that these specimens belong to $P$. isaki. This species, characterised by a weakly developed anterior oesophageal inflation, was described by Quiazon et al. (2008a) from the gonads of $P$. trilineatum in the East China Sea off Japan. However, conspecific nematodes (only females) from the gonads of the same host species $(P$. trilineatum) off Japan were earlier reported by Yamaguti (1935), who had considered them to be identical with $P$. lateolabracis. Distinction between $P$. lateolabracis and $P$. isaki was clearly proved by Quiazon et al. (2008a), who were the first to discover and describe the males of both these species.

\section{Philometra sp.}

Fig. 12

Subgravid female (1 specimen). Body robust, that of fixed specimen yellowish, elongate, with anterior part somewhat broader than posterior one. Length of body $260 \mathrm{~mm}$, maximum width $1.70 \mathrm{~mm}$. Anterior end somewhat narrowed, rounded; width of cephalic end 313

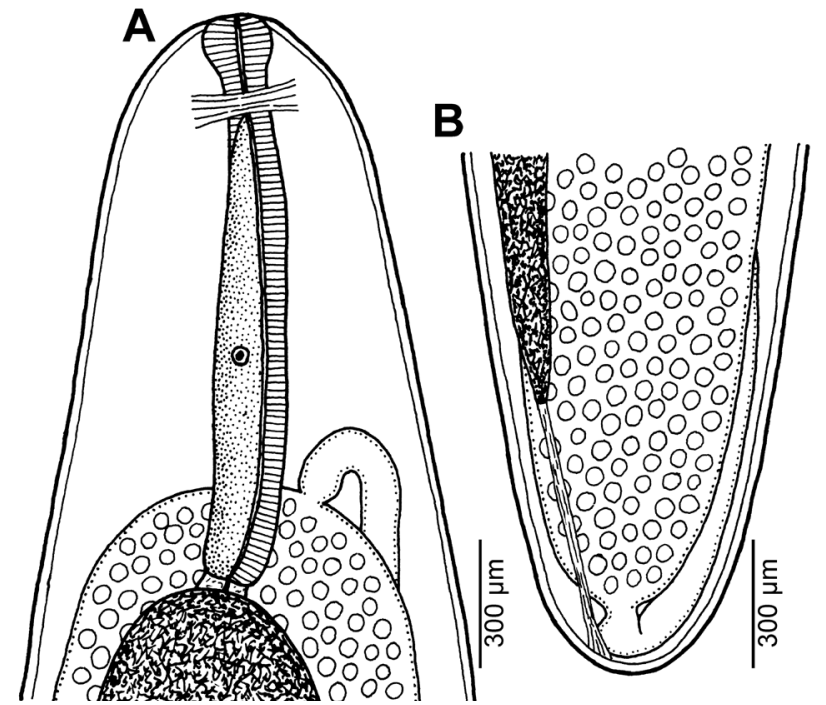

Fig. 12. Philometra sp. from Synanceia verrucosa Bloch et Schneider, subgravid female. A, B - anterior and posterior ends of body, respectively, lateral views.

(Fig. 12A). Cuticle smooth. Maximum width/length ratio of body $1: 153$. Cephalic papillae very small, almost indistinct in lateral view; papillae arranged in 2 circles: 4 submedian pairs of papillae of outer circle and 6 single papillae (4 submedian and 2 lateral) of inner circle. Oesophagus swollen near mouth to form distinct bulb 136 long and 177 wide. Overall length of oesophagus including anterior bulb $1.51 \mathrm{~mm}$, representing $0.7 \%$ of body length, maximum width of its cylindrical part 177 . Oesophageal gland well developed, extending from level of nerve ring to posterior end of oesophagus, containing large cell nucleus at its middle (Fig. 12A). Small ventriculus present. Nerve ring 231 from anterior end of body. Intestine wide, light-coloured, its posterior end atrophied, attached subterminally to ventral body wall by short ligament (Fig. 12B). Vagina and vulva absent. Ovaries reflected, situated near anterior and posterior ends of body (Fig. 12A,B). Uterus extending anteriorly to base of oesophagus and posteriorly nearly to posterior extremity, being filled with large number of eggs (Fig. 12A,B). Posterior end of body rounded, without caudal projections (Fig. 12B).

Host: Stonefish, Synanceia verrucosa Bloch et Schneider (Synanceiidae, Scorpaeniformes).

Site of infection: Ovary.

L o c a li t y: Western North Pacific Ocean off Yonashiro, Uruma City, Okinawa Prefecture, Japan (collected on 22 April 2010). Prevalence and intensity: 1 fish infected/1 fish examined; 2 nematodes.

Deposition of specimen: IPCAS N-1197.

Remarks. To date, the only species of Philometra reported from fishes of the family Synanceiidae is $P$. inimici Yamaguti, 1941, originally described by Yamaguti (1941) from a single gravid female found in the abdominal cavity of Inimicus japonicus (Cuvier) from Japan (Hamazima) and later redescribed based on available females from the ovary of the same host species in the Sea of Japan 
by Moravec et al. (1998). Rasheed (1963) synonymised Philometra cryptocentri Yamaguti, 1961 from the abdominal cavity of Cryptocentrus filifer (Valenciennes) (Gobiidae) in Japan with $P$. inimici and this was followed by Moravec and Nagasawa (1989) and Moravec et al. (1998). Moreover, Moravec and Nagasawa (1989) identified females of Philometra from the testis of Platycephalus indicus (Linnaeus) (Platycephalidae) in Japan as P. inimici. However, taking into account a high degree of host specificity of gonad-infecting species of Philometra (see Moravec et al. 2016) and the fact that all these forms were described solely from females whereas conspecific males remain unknown, it is almost sure that the above-mentioned philometrids from other fish families (Gobiidae or Platycephalidae) do not belong to $P$. inimici. Therefore, $P$. cryptocentri was re-erected by Moravec (2006) and the specimens from the gonads of $P$. indicus should be designated as Philometra sp.

The morphology of the present female nematodes somewhat resembles that of $P$. inimici, but since only one complete and one incomplete subgravid specimens were available to study, these are designated only as Philometra sp.

\section{Congerinema gen. n.}

ZooBank number for species:

urn:1sid:zoobank.org:act:ED7AA785-FB87-400D-A7AE-B0B7E26BB052

Diagnosis: Philometridae. Body of females elongated, cylindrical, with bluntly rounded ends. Conspicuous netlike ornamentation formed by cuticular moulds extends nearly throughout body, appearing at body margin as small cuticular bosses. Cephalic papillae small, arranged in two circles. Oesophagus cylindrical, expanded at anterior end to form large bulbous inflation; oesophageal gland inconspicuous, with moderately developed cell nucleus at middle; small ventriculus present. Vulva and anus in gravid females atrophied. Ovaries in both body ends. Males not known. Parasites of subcutaneous tissue of marine fishes.

Type species: Congerinema.japonicum sp. $\mathrm{n}$.

Etymology: The generic name is composed of two parts: "congeri" derived from the generic name of the host fish (Conger) and "nema" (= nematode). The name is neuter gender.

\section{Congerinema japonicum sp. $\mathbf{n}$.}

Figs. 13, 14

ZooBank number for species:

urn:1sid:zoobank.org:act:A534A875-4F46-4489-9448-D0E8592C259F

Gravid female (4 specimens; measurements of holotype in parentheses): Body of fixed specimens yellowish, filiform, 260-370 (280) mm long, maximum width 1.01-1.27 (1.18) mm; width of cephalic end 245-340 (258), width of caudal end 150-585 (204). Body surface with conspicuous cuticular net-like ornamentation extending approximately from level of nerve ring to posterior end of body, appearing at body margin as small cuticular bosses (Figs. 13F,G, 14C,D). Maximum width/length ratio of body $1: 237-292$ (1 : 237). Anterior end of body somewhat narrowed, roun- ded (Fig. 13A). Oral aperture oval, surrounded by 14 small cephalic papillae arranged in 2 circles; external circle formed by 4 submedian pairs of papillae; internal circle consists of 4 submedian subventral and 2 lateral single papillae; small amphids present, located slightly posterior to lateral cephalic papillae (Figs. 13C, 14A,B). Oesophagus narrow, swollen near mouth to form conspicuous bulb 190-218 (204) long and 218-245 (245) wide, distinctly separated from posterior cylindrical part of oesophagus; bulb with spacious, transversely oval buccal cavity 21-39 (24) long and 96-105 (102) wide (Fig. 13A,B). Oesophagus including anterior bulb 1.24-1.40 (1.40) mm long, representing $0.4-0.5 \%(0.5 \%)$ of body length; maximum width of its cylindrical part 136-190 (136). Oesophageal gland weakly developed, indistinct, extending from level of nerve ring to end of oesophagus, with poorly visible cell nucleus at its middle (Fig. 13A). Nerve ring 231-258 (258) from anterior end of body. Small ventriculus 27-41(41) long, 68-95 (95) wide. Intestine comparatively narrow, light-coloured, ending blindly; its posterior end atrophied, forming short ligament 150-340 (204) long, attached ventrally to body wall near posterior extremity (Fig. 13E). Two ovaries rather long, reflected, situated near anterior and posterior ends of body (Fig. 13A,E). Uterus containing numerous eggs and larvae extends anteriorly to level of nerve ring and posteriorly to body end (Fig. 13A,E). Larvae $(n=5)$ 453-507 long and 18-21 wide, their oesophagus 114-120 long (22-26\% of body length) and sharply pointed tail $75-$ 87 long (16-19\% of body length) (Fig. 13D). Posterior end of female rounded, without caudal projections (Fig. 13E).

Male: Not known.

Type host: Whitespotted conger, Conger myriaster (Brevoort) (Congridae, Anguilliformes).

Site of infection: Under skin.

Type locality: Unknown locality in the western North Pacific Ocean or the Seto Inland Sea, Japan (collected on 6 September 1978).

Prevalence and intensity: Single fish examined being infected with 4 nematodes.

Deposition of type specimens: IPCAS N-1195.

Etymology: The specific name of this nematode relates to the country of its occurrence.

Remarks. Since the males of many philometrid species remain unknown, the present classification system of these nematodes is based essentially on the number, arrangement and character of female cephalic papillae and the structure of various cuticular ornamentations, which are considered the main taxonomic features (Rasheed 1963, Ivashkin et al. 1971, Moravec 2006, Anderson et al. 2009). The hitherto monotypic genus Congerinema gen. n. differs from other philometrid genera with cuticular ornamentations mainly in that the cuticular moulds on the body surface of its gravid females have a net-like pattern. In contrast, species of Spirophilometra Parukhin, 1971 have a cuticle densely covered with minute spines, those of Buckleyella Rasheed, 1963, Caranginema Moravec, Montoya-Mendoza et Salgado-Maldonado, 2008, Nilonema Khalil, 1960, Paraphilometroides Moravec et Shaharom-Harisson, 1989 

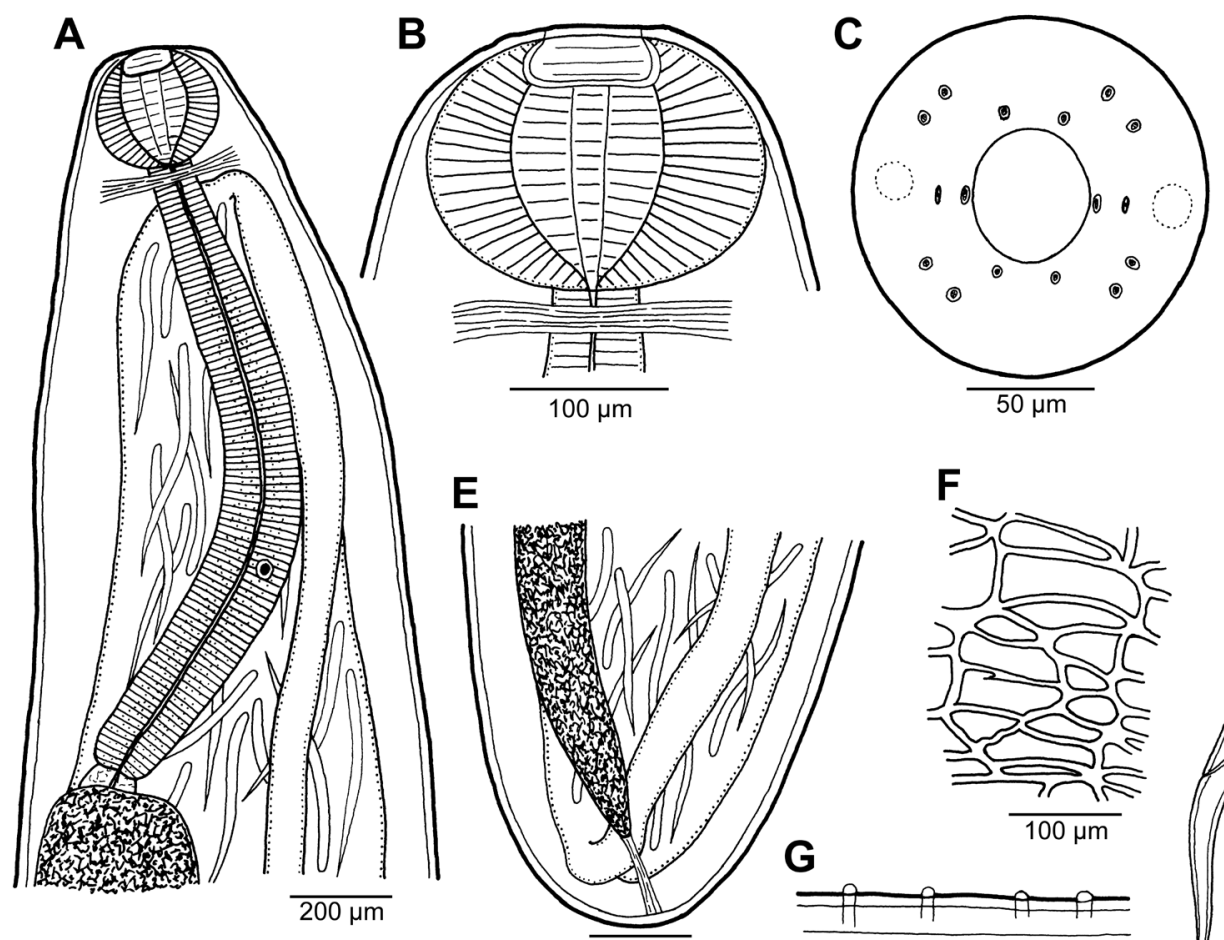

D

\section{E}

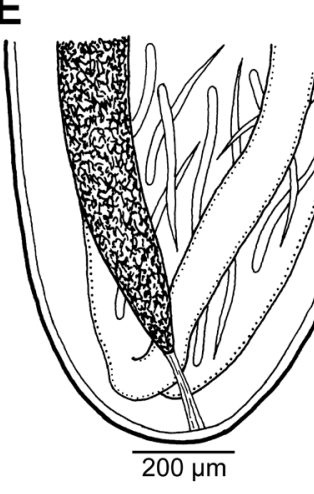

$\mathbf{F}$

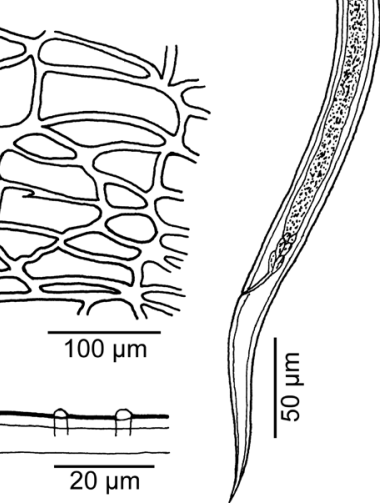

Fig. 13. Congerinema japonicum gen. et sp. $\mathrm{n}$. from Conger myriaster (Brevoort), gravid female. $\mathbf{A}$ - anterior end of body, lateral view; $\mathbf{B}$ - anterior bulbous inflation of oesophagus; $\mathbf{C}$ - cephalic end, apical view; $\mathbf{D}$ - larva from uterus, lateral view; $\mathbf{E}$ - caudal end, lateral view; $\mathbf{F}$ - net-like cuticular ornamentation on middle part of body; $\mathrm{G}$ - cuticular ornamentation at body side appearing as small papillae.
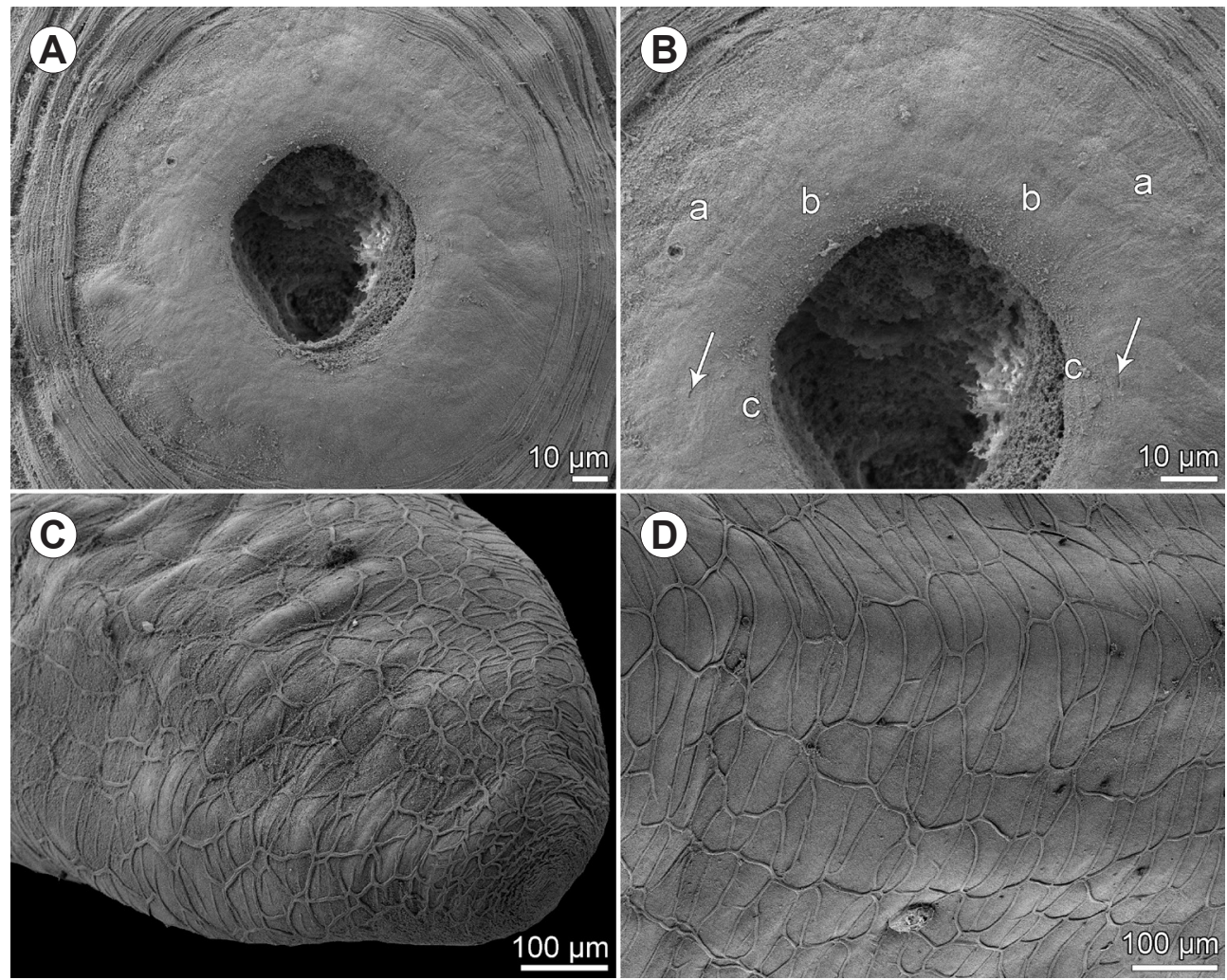

Fig. 14. Congerinema japonicum gen. et sp. n. from Conger myriaster (Brevoort), scanning electron micrographs of gravid female. $\mathbf{A}$ - cephalic end, apical view; $\mathbf{B}$ - enlarged region of oral aperture, apical view (arrows indicate amphids); $\mathbf{C}$ - caudal end, lateral view; D - net-like cuticular ornamentation on middle part of body. Abbreviations: a - submedian pair of cephalic papillae of outer circle; $\mathrm{b}$ - submedian cephalic papilla of inner circle; $\mathrm{c}$ - lateral cephalic papilla of inner circle. 

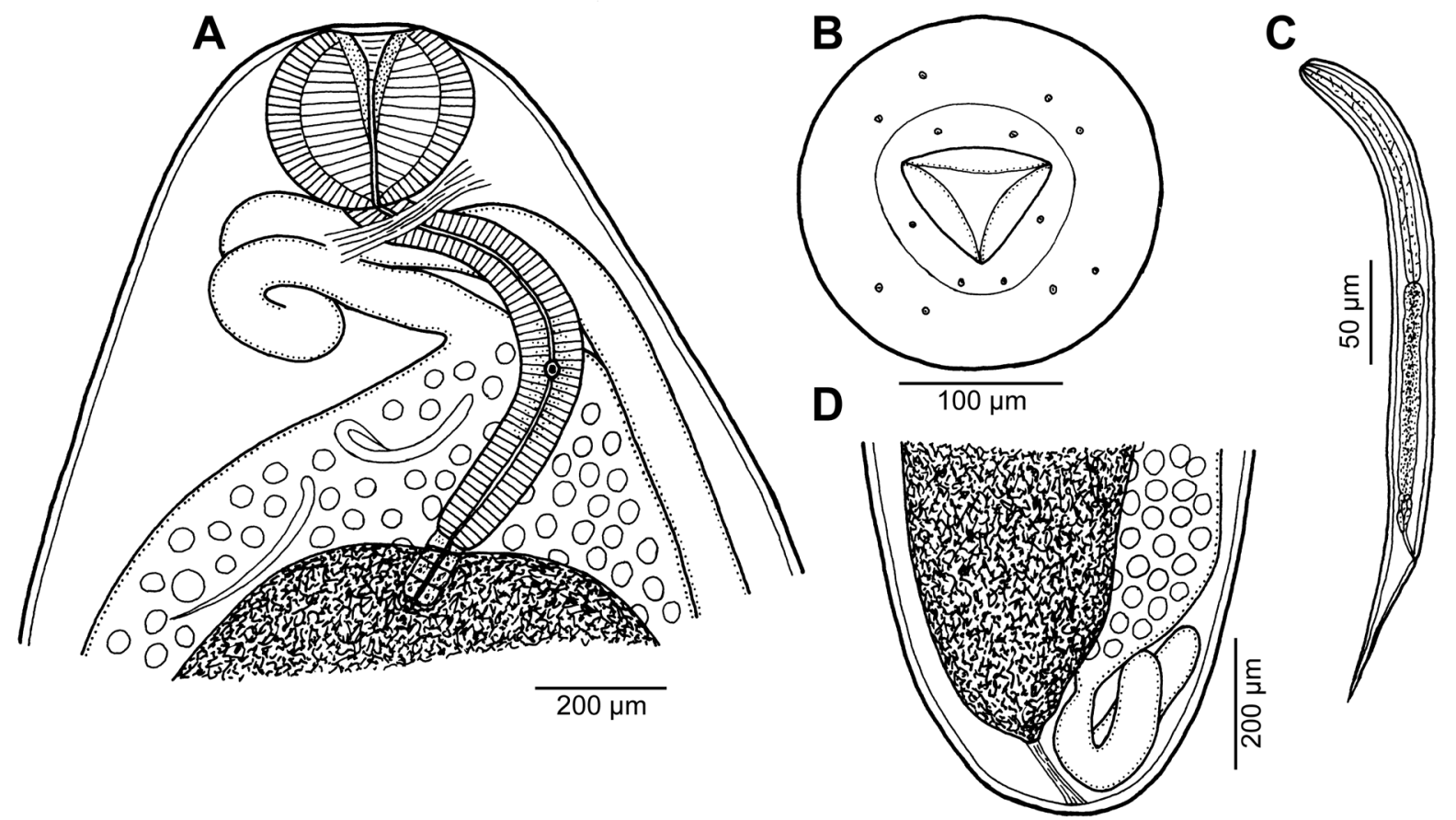

Fig. 15. Clavinema mariae (Layman, 1930) from Acentrogobius pflaumii (Bleeker), gravid female. A - anterior end, lateral view; $\mathbf{B}$ - cephalic end, apical view; C - larva from uterus, lateral view; D - posterior end, lateral view.

and Philometroides possess other cuticular structures, namely individual bosses, cone-shaped or short transverse excrescences or rod-like structures, Afrophilometra Moravec, Charo-Karisa et Jirků, 2009 has the body surface with many transverse semicircular bands of inflated cuticle interrupted by narrow smooth lateral fields, and Clavinemoides Moravec, Khoshheghbal et Pazooki, 2013 is characterised by a distinctly annulated body and numerous fine elevated transverse cuticular bands (Moravec 2006, Moravec et al. 2008b, 2009, 2013).

To date, C. japonicum sp. n. is the only philometrid nematode described from the Congridae. Filaria congeri-vulgaris Molin, 1859, described from the stomach of Conger conger (Linnaeus) in Padova, Italy (Molin 1859) and later incorrectly transferred by Yorke and Maplestone (1926) to Philometra as Philometra congerivulgaris (considered a species inquirenda by Rasheed 1963), was in fact an anisakid nematode (Moravec 2006).

\section{Clavinema mariae (Layman, 1930) Margolis et} Moravec, 1987

Figs. 15, 16

Syns.: Philometra mariae Layman, 1930; Philometra americana Kuitunen-Ekbaum, 1933; Philometra zebrini Yamaguti, 1961.

Gravid female (1 specimen). Body of fixed specimen whitish, plump, with smooth cuticle; posterior half of body distinctly narrower than anterior one. Length of body 29.8 $\mathrm{mm}$, maximum width $1.70 \mathrm{~mm}$; maximum width/body length ratio $1: 18$. Cephalic end rounded, 517 wide (Fig. $15 \mathrm{~A}$ ); width of posterior body end 218 . Oral opening triangular, large (Figs. 15B, 16A,B), surrounded by 4 submedian pairs of very small, hardly visible cephalic papillae of outer circle and by 6 minute single papillae (2 lateral and 4 submedian) distributed near edge of oral aperture. Anterior end of oesophagus forming conspicuous, strongly muscular bulb, well separated from cylindrical portion of oesophagus; bulb 299 long, 354 wide. Greater, posterior portion of oesophagus cylindrical, 857 long and 122 wide; oesophageal gland small, difficult to observe; cell nucleus of gland inconspicuous, located 680 from anterior extremity of body. Length of entire oesophagus including anterior bulb $1.16 \mathrm{~mm}$, representing 3.9\% of body length (Fig. $15 \mathrm{~A})$. Small ventriculus present. Oesophagus opening into intstine through distinct valve. Nerve ring 340 from anterior extremity. Intestine light-brown, very wide; its posterior end attached by short ligament, 109 long, to body wall near posterior end of body. Ovaries located near body ends (Fig. $15 \mathrm{~A}, \mathrm{~B})$. Uterus occupying major part of body space, reaching anteriorly to mid-length of oesophagus and posteriorly to level of posterior end of intestine. Uterus containing mostly eggs, but also several larvae (Fig. 15A,D). Larvae 303-360 long, 15-18 wide, length of oesophagus 114-120 (33-38\% of body length), of sharly pointed tail 60-84 (20$23 \%$ of body length) (Fig. 15C). Posterior end of female body rounded, without any projections (Fig. 15D).

Male. Not known.

Host: Striped sandgoby, Acentrogobius pflaumii (Bleeker) (Gobiidae, Perciformes).

Site of infection: Under the skin of the operculum.

Locality: Seto Inland Sea off Fukuyama City, Hiroshima Prefecture, Honshu, Japan (collected in August 2017).

Prevalence and intensity: 1 fish infected/1 fish examined; 1 nematode.

Deposition of voucher specimen: IPCAS N-195. 

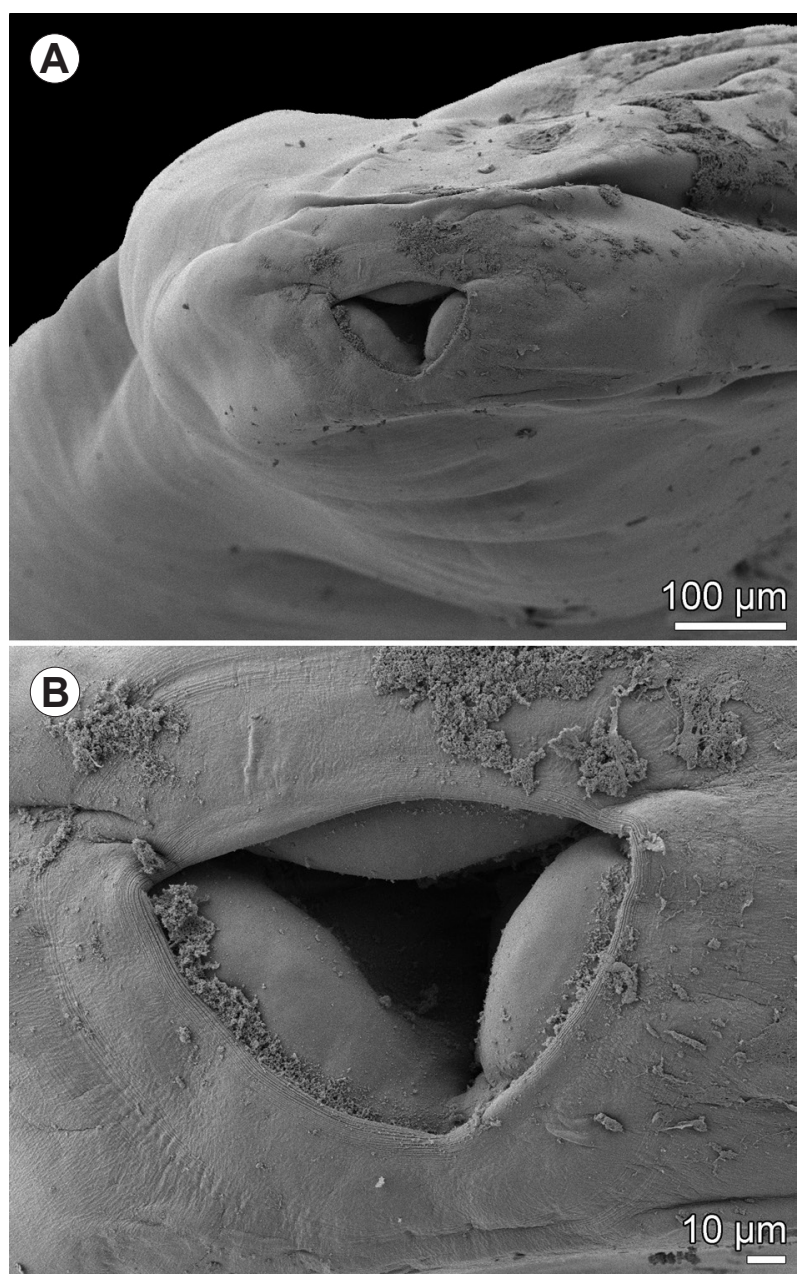

Fig. 16. Clavinema mariae (Layman, 1930) from Acentrogobius pflaumii (Bleeker), scanning electron micrographs of gravid female. A - cephalic end, apical view; B - region of oral aperture, apical view (minute cephalic papillae indistinct).

Remarks. Gravid females of philometrids from the subcutaneous tissue of two gobiid species, Acentrogobius virgatulus (Jordan et Snyder) and Amblychaeturichthys sciistius Jordan et Snyder [as Rhinogobius pflaumi (Bleeker) and Chaeturichthys sciistius (Jordan et Snyder), respectively] in Japan were previously reported from the Seto Inland Sea by Yamaguchi et al. (1973) and Sakaguchi and Fukuhara (1975) as Philometra mariae. It is apparent that these were conspecific with the present nematode. The finding of $C$. mariae in A. pflaumii represents a new host record.

In Japan, morphologically very similar specimens (gravid females) were reported as Clavinema mariae also from the subcutaneous tissue of the gobiid Acanthogobius flavimanus (Temminck et Schlegel) and the pleuronectid Pseudopleuronectes schrenki (Schmidt) by Moravec et al. (1998). However, only the cephalic end of specimens from the latter host was studied by SEM and the oral aperture proved to be distinctly triangular in shape.

According to the key to the philometrid genera based on female morphology by Moravec et al. (2013), there are only two genera characterised by the triangular oral aperture, Clavinema and Clavinemoides, whereas that in all other genera is circular or oval. The triangular mouth was reported for Clavinema parasiluri Yamaguti, 1935 (type species) by Yamaguti (1935) and for Clavinema fujimotoi (Furuyama, 1932) by Wu and Huang (1964), whereas the triangular mouth in $C$. mariae parasitising the Pleuronectidae in the North Pacific region was found by Moravec et al. (1998).

Clavinema mariae was originally described by Layman (1930) as Philometra mariae from females in the fins of Cleisthenes herzensteini (Schmidt) and P. schrenki (both Pleuronectidae) of the Sea of Japan; he also reported it from the ovary of $S$. schlegelii, but probably it concerned a different philometrid species (see Moravec and Nagasawa 1985, Moravec et al. 1998). Machida (1970) reported this species (as Philometra) from the fins and opercula of Pseudopleuronectes yokohamae (Günther) (as Limanda yokohamae) (Pleuronectidae) in Otsuchi Bay, Japan. Later Margolis and Moravec (1987) formally transferred $P$. mariae to Clavinema and synonymised $P$. americana and P. zebrini, mostly reported from pleuronectiform fishes, with $C$. mariae. They also identified female specimens found in the subcutaneous connective tissue of Cottus asper Richardson (Cottidae) in western Canada as C. mariae. According to Moravec (2006), C. mariae, a parasite mainly of Pleuronectiformes, has also been reported from nine host species belonging to Gobiesociformes (Gobiesocidae, Pholidae), Perciformes (Gobiidae, Stichaeidae) and Scorpaeniformes (Cottidae, Sebastidae).

In addition, females of $C$. mariae were found by $\mathrm{Bu}-$ torina and Skiba (2001) in the subcutaneous tissues and fins of Opisthocentrus ocellatus (Tilesius) (Stichaeidae, Perciformes), Pleuronectes obscurus (Herzenstein) (Pleuronectidae, Pleuronectiformes), Hexagrammos octogrammus (Pallas) (Hexagrammidae, Scorpaeniformes) and S. schlegelii (Sebastidae, Scorpaeniformes) in the Sea of Okhotsk off eastern Russia. Subsequently, Markevich and Butorina (2005) reported C. mariae females from six species of fishes, Alectrias cirratus (Lindberg), Opisthocentrus zonope Jordan et Snyder and Stichaeopsis epallax (Jordan et Snyder) (all Stichaeidae, Perciformes), Neozoarces steindachneri Jordan et Snyder (Zoarcidae, Perciformes), Sebastes taczanowskii Steindachner (Sebastidae, Scorpaeniformes) and the pleuronectid P. yokohamae, in the Sea of Japan (Peter the Great Bay) off eastern Russia.

Although these parasites were generally found located in the hosts' subcutaneous tissues and fins, haevy infections of C. mariae were allegedly observed in the gonads of S. taczanowskii. However, Sokolov et al. (2010) correctly considered the identification of these nematodes from fish gonads to be doubtful. Moreover, Sokolov et al. (2010) reported females of $C$. mariae from the subcutaneous tissues of fins, opercula, the wall of orbits and from the mouth cavity of the gadiform fish Eleginus gracilis (Tilesius) (Gadidae) in the Sea of Okhotsk, off Sakhalin, eastern Russia.

Taking into account a relatively high degree of host specificity in philometrids and, on the other hand, the reported hosts of $C$. mariae belonging to five different fish orders, it is highly probable that $C$. mariae represents a complex of related species with almost identical female morphology. Some interspecific differences might be evi- 
dent from the morphology of males, like in the case of numerous gonad-infecting species of Philometra. However, to date, the males of $C$. mariae remain unknown. Nevertheless, as revealed by SEM, the oral aperture of $C$. mariae females from P. schrenki is triangular (Moravec et al. 1998), i.e., typical of Clavinema, which confirms the belonging of these nematodes to this genus. Even though the specimens of $C$. mariae from other pleuronectiform hosts have not yet been examined by SEM, they probably belong to the same species.

In contrast, the SEM study of nematodes reported as $C$. mariae from S. schlegelii in Korea by Han et al. (2017) shows clearly that the mouth of their specimens was circular, indicating that these nematodes did not belong to Clavinema but to Philometra and should be designated as Philometra sp. However, the female mouth of the present specimen from $A$. pflaumii, as well as that of specimens reported as $C$. mariae from $E$. gracilis (see above), both studied with the use of SEM, is triangular, i.e., characteristic of Clavinema. However, other nematodes reported as $C$. mariae from hosts belonging to other fish orders than Pleuronectiformes (see above) have not yet been examined by SEM, so that their generic appurtenance remains uncertain.

Since $C$. mariae is probably a complex of several similar species (see above), it is very important to discover and describe the males of these nematodes from different hosts, as well as to study available females by SEM, or to use molecular methods to distinguish possible cryptic species. For the time being, the present specimen from $A$. pflaumii is identified as C. mariae.

\section{DISCUSSION}

Philometrids are a diverse group of parasites with a worldwide distribution that is characterised, like other dracunculoids, by specific morphological features and some biological peculiarities (Moravec 2006). Some species are pathogenic parasites of fish with economic importance, in stocks of both free-living and cultured fish. To date, most species of philometrids are known solely by their largesized and frequently red-couloured females, whereas conspecific males are very small (usually about 2-4 $\mathrm{mm}$ long) and escape attention during routine fish dissections.
Regarding philometrids parasitising marine fishes off Japan, for a long time all these nematode species were known solely by females (Ishii 1931, Yamaguti 1935, 1941, 1961, Machida 1970, Sakaguchi and Matsusato 1978, Nakajima and Egusa 1979, Sakaguchi et al. 1987a), until Moravec et al. (1998) described, based on LM, the male of Philometra sciaenae from the type host. Later Quiazon et al. (2008a,b), with the use of both LM and SEM, described, for the first time, the males of Philometra lateolabracis (Yamaguti, 1935), Philometra nemipteri Luo, 2001 and those of three other newly established congeneric species and redescribed the male of P. sciaenae. Their work showed, for the first time, the importance of male morphology studied by SEM, especially the ultrastructure of the gubernaculum, for the taxonomy of Philometra spp. Subsequently, this made possible to discover and describe many new gonad-infecting species of Philometra, whose females are morphologically very similar, and to recongnise a rather high degree of host specificity among these parasites (Moravec et al. 2016).

Nevertheless, of the 22 species of philometrids presently recorded from marine fishes in Japan, the conspecific males are known only for six gonad-infecting representatives of Philometra ( $P$. isaki, P. lateolabracis, $P$. madai, $P$. nemipteri, $P$. sciaenae and $P$. sawara Quiazon, Yoshinaga et Ogawa, 2008), all parasites of perciform fishes. Therefore, the discovery of males of other 16 species of philometrids from Japanese marine fishes is needed.

Acknowledgements. We thank the following persons who gave us the opportunity to examine nematodes: Yutaka Fukuda of the Fisheries Research Division, Oita Prefectural Agriculture, Forestry and Fisheries Research Center, Takahiro Nagai of the Hiroshima Prefectural Fisheries and Marine Technology Center and Hidenori Yoshigou of the Chugai Technos. Thanks are also due to the Laboratory of Electron Microscopy, Institute of Parasitology, Biology Centre CAS, institution supported by the MEYS CR (LM2015062 Czech-BioImaging), for their support with obtaining scientific data presented in this paper, and to Blanka Škoríková of the same Institute for help with illustrations. Sergey G. Sokolov, Institute of Ecology and Evolution, Russian Academy of Sciences, Moscow kindly provided some hardly accessible Russian literature. This study was partly supported by the institutional support of the Institute of Parasitology, BC AS CR (585110/9500).

\section{REFERENCES}

Anderson R.C., Chabaud A.G., Willmott S. (Eds.) 2009: Keys to the Nematode Parasites of Vertebrates. CAB International, Wallingford, $463 \mathrm{pp}$.

Butorina T.E., Skiba I.I. 2001: [Parasites of fishes of bay Severnaya of Slavyanka Bay.] Nauch. Tr. Dal'nevost. Gos. Tekhn. Rybokhozyayst. Univ. 14: 102-105. (In Russian.)

Dewi K., Palm H.W. 2013: Two new species of philometrid nematodes (Nematoda: Philometridae) in Epinephelus coioides (Hamilton, 1822) from the South Bali Sea, Indonesia. Zootaxa 3609: 049-059.

Froese R., Pauly D. (Eds.) 2019: FishBase. World Wide Web electronic publication, http://www.fishbase.org, version 06/2019.

Han H.-J., Seo J.S., Park J.S., Lee H.L., Seo H.G., Jung H.G., Kwon S.R. 2017: First report of Clavinema mariae (Nemato- da: Philometridae) in cultured rockfish, Sebastes schlegeli, in Cheonsuman (bay), the Republic of Korea. Kor. J. Parasitol. 55: 219-224.

IsHII S. 1931: [Parasites of fishes of Japan.] Biology. Iwanami Publ. Comp., Tokyo. Pt. 18, pp. 179-207. (In Japanese.)

Ivashí in V.M., Sobolev A.A., Khromova L.A. 1971: [Camallanata of Animals and Man and the Diseases Caused by Them. Osnovy Nematodologii 22.] Nauka, Moscow, 388 pp. (In Russian.)

Ko R.C., Chan S.-W. 2002: A Preliminary Study of the Parasite Fauna of Three Common Marine Fish of Hong Kong (Siganus fuscescens, Sebastiscus marmoratus, Epinephelus akaara). The University of Hong Kong Occasional Publication, Department of Zoology, Hong Kong, 71 pp. 
Layman E.M. 1930: [Parasitic worms from fishes of Peter the Great Bay.] Izv. Tikhookeansk. Nauch.-promysl. Stantsii, Vladivostok, 3: 1-120. (In Russian with German abstract.)

Levashov M.M. 1929: [On the biology of Philometra rischta Skrjabin 1923.] Rab. Volzhsk. Biol. Stantsii, Saratov, 10: 211-214. (In Russian with German abstract.)

Linton E. 1907: Notes on parasites of Bermuda fishes. Proc. U. S. Nat. Mus. 33: 85-126.

MACHIDA M. 1970: [Philometra mariae Layman, 1930 from a right-eyed flounder, Limanda yokohamae.] Fish Pathol. 5: 21-24. (In Japanese with English abstract.)

Margolis L., Moravec F. 1987: A record of Clavinema mariae (Layman, 1930) (Nematoda: Philometridae) from a North American freshwater fish, with notes on the systematic status of Philometra americana Kuitunen-Ekbaum, 1933. Folia Parasitol. 34: 31-37 + Pl. I.

Marino F., Busalacchi B., Bottari T., Rinelli P., Gaglio G. 2016: Occurrence and prevalence of Philometra filiformis (Stossich, 1896) on Pagellus erythrinus (Linnaeus, 1758) in the southern Tyrrhenian Sea. J. Appl. Ichthyol. 32: 687-692.

Markevich A.I., Butorina T.E. 2005: Pathologies and invasions by parasites of some marine fishes off Bol'shoy Pelis Island (Far East Marine Biosphere Reserve). Voprosy Rybolovstva [Problems of Fisheries] 6: 781-790. (In Russian with English abstract.)

Molin R. 1859: Abhandlungen und Mittheilungen. Sitzungsber. Akad. Wissensch. Wien 38: 7-38.

MolnáR K. 1966: Life-history of Philometra ovata (Zeder, 1803) and Ph. rischta Skrjabin, 1917. Acta Vet. Acad. Sci. Hung. 16: 227-242.

Moravec F. 2006: Dracunculoid and Anguillicoloid Nematodes Parasitic in Vertebrates. Academia, Prague, 634 pp.

Moravec F. 2013: Parasitic Nematodes of Freshwater Fishes of Europe. Revised second edition. Academia, Prague, $601 \mathrm{pp}$.

Moravec F., Bakenhaster M.D., Adams D.H. 2016a: Two new species of Philometra Costa, 1845 (Nematoda: Philometridae) from Mycteroperca spp. (Serranidae) in the North-West Atlantic and northern Gulf of Mexico, USA. Syst. Parasitol. 93: 479-491.

Moravec F., Bakenhaster M.D., Fajer-Ávila E.J. 2014: Three new gonad-infecting species of Philometra (Nematoda: Philometridae) parasitic in Lutjanus spp. (Lutjanidae) in the northern Gulf of Mexico off Florida, USA. Folia Parasitol. 61: 355-369.

Moravec F., Cutmore S.C., Yong R.Q-Y. 2018: Redescription of Philometra pellucida (Jägerskiöld, 1893) (Nematoda: Philometridae) parasitic in the abdominal cavity of the blackspotted puffer Arothron nigropunctatus (Bloch \& Schneider) (Teleostei: Tetraodontidae). Syst. Parasitol. 95: 665-671.

Moravec F., DE Buron I. 2009: Two new species of philometrids (Nematoda: Philometridae) from marine fishes off South Carolina. J. Parasitol. 95: 722-727.

Moravec F., Chaabane A., Neifar L., Gey D., Justine J.-L. 2016b: Descriptions of Philometra aenei n. sp. and P. tunisiensis n. sp. (Nematoda: Philometridae) from Epinephelus spp. off Tunisia confirm a high degree of host specificity of gonad-infecting species of Philometra in groupers (Serranidae). Syst. Parasitol. 93: 115-128.

Moravec F., Charo-Karisa H., Jirků M. 2009: Philometrids (Nematoda: Philometridae) from fishes of Lake Turkana, Kenya, including two new species of Philometra and erection of Afrophilometra gen. sp. Folia Parasitol. 56: 41-54.

Moravec F., De Buron I. 2013: A synthesis of our current knowledge of philometrid nematodes, a group of increasingly important fish parasites. Folia Parasitol. 60: 81-101.

Moravec F., Diggles B.K. 2014: Philometrid nematodes (Philometridae) from marine fishes off the northern coast of Australia, including three new species. Folia Parasitol. 61: 37-54.

Moravec F., Gaglio G., Panebianco A., Giannetto S. 2008a: Two species of Philometra (Nematoda: Philometridae) from sparid fishes (porgies) off Sicily, Italy, including Philometra obladae sp. n. from the body cavity of Oblada melanura (Sparidae). Parasitol. Res. 104: 55-61.
Moravec F., Genc E. 2004: Redescription of three Philometra spp. (Nematoda: Philometridae) from the gonads of marine perciform fishes of Iskenderun Bay (North-East Mediterranean), Turkey. Acta Parasitol. 49: 31-40.

Moravec F., Ghanmi N., Chaabane A., Gargouri L., JustiNE J.-L. 2017: Redescription of Philometra filiformis (Stossich, 1896) (Nematoda: Philometridae), a gonad-infecting parasite of the common pandora Pagellus erythrinus (Linnaeus) (Sparidae) in the Mediterranean Sea, including new taxonomic features revealed by SEM. Syst. Parasitol. 94: 979-987.

Moravec F., Jassim A.A.R., Al-Salim N.K. 2012b: Philometroides acanthopagri sp. nov., a new philometrid (Nematoda, Philometridae) from the musculature of Acanthopagrus latus (Sparidae) from marine waters of Iraq. Acta Parasitol. 57: 372-377.

Moravec F., Khosheghbal M., Pazooki J. 2013: Two philometrids (Nematoda: Philometridae) infecting the tigertooth croaker Otolithes ruber (Bloch \& Schneider) (Teleostei: Sciaenidae) off Iran, including erection of a new genus. Syst. Parasitol. 86: $33-41$.

Moravec F., Montoya-Mendoza J., Salgado-Maldonado G. 2008b: A new genus and species of philometrid (Nematoda) from the subcutaneous tissue of the crevalle jack, Caranx hippos (Osteichthyes), from the southern Gulf of Mexico. J. Parasitol. 94: 1346-1350.

Moravec F., Nagasawa K. 1985: Ichthyofilaria japonica sp. n. (Philometridae) and some other nematodes from marine fishes from Hokkaido, Japan. Acta Soc. Zool. Bohemoslov. 49: 211-223.

Moravec F., Nagasawa K. 1989: Three species of philometrid nematodes from fishes in Japan. Folia Parasitol. 36: 143-151.

Moravec F., Nagasawa K., Nohara K. 2012a: Two species of philometrid nematodes (Philometridae) from marine fishes off Japan, including Philometroides branchiostegi sp. n. from Branchiostegus japonicus (Malacanthidae). Folia Parasitol. 59: 71-78.

Moravec F., Nagasawa K., Ogawa K. 1998: Observations on five species of philometrid nematodes from marine fishes in Japan. Syst. Parasitol. 40: 67-80.

Moravec F., Ogawa K., Suzuki M., Miyazaki K., Donai H. 2002: On two species of Philometra (Nematoda: Philometridae) from the serranid fish Epinephelus septemfasciatus in Japan. Acta Parasitol. 47: 34-40.

NAGasawa K. 2008: [Synopsis of nematodes of the superfamilies Dracunculoidea and Anguillicoloidea parasitic in fishes and amphibians of Japan (1916-2008).] Bull. Biogeogr. Soc. Japan 63: 111-124. (In Japanese with English abstract.)

Nakajima K., EguSa S. 1979: [Philometra sp. found on the gonad of cultured Red sea bream. Fish Pathol. 13: 197-200. (In Japanese with English abstract.)

Quiazon K.M.A., Yoshinaga T., Ogawa K. 2008a: Taxonomical study into two new species of Philometra (Nematoda: Philometridae) previously identified as Philometra lateolabracis (Yamaguti, 1935). Folia Parasitol. 55: 29-41.

Quiazon K.M.A., Yoshinaga T., Ogawa K. 2008b: Philometra sawara sp. n. and a redescription of Philometra sciaenae Yamaguti, 1941 and Philometra nemipteri Luo, 2001 (Nematoda: Philometridae): a morphological and molecular approach. Folia Parasitol. 55: 277-290.

Rasheed S. 1963: A revision of the genus Philometra Costa, 1845. J. Helminthol. 37: 89-130.

Sakaguchi S., Fukuhara O. 1975: [Studies on a nematode, Philometra, in the marine benthic fishes - II. Morphology of the larvae and experimental infection to the intermediate host.] Bull. Nansei Reg. Fish. Res. Lab. 8: 1-10. (In Japanese with English abstract.)

Sakaguchi S., Matsusato T. 1978: [On a nematode, Philometra found in a Red sea bream, Chrysophrys major - I. Bull.] Nansei Reg. Fish. Res. Lab. 11: 27-32. (In Japanese with English abstract.)

Sakaguchi S., Shibahara T., Yamagata Y. 1987b: [Parasitic ekology of a Philometra lateolabracis on the Red sea bream.] Bull. Nat. Res. Inst. Aquacult. 12: 73-78. (In Japanese with English abstract.) 
SAKaguchi S., Yamagata Y., Sako H. 1987a: [Reidentification of Philometra parasitic on the Red sea bream.] Bull. Nat. Res. Inst. Aquacult. 12: 69-72. (In Japanese with English abstract.)

SKRJABin K.I. 1923: Philometra rischta mihi, eine interessante Fischfilaria aus Sibirien. Russ. Gidrobiol. Zhur. 2: 236-240.

Sokolov S.G., Frolova S.E., Frolov E.V. 2010: [The first record of parasitic nematode Clavinema mariae (Dracunculoidea: Philometridae) in gadiform fishes (Osteichthyes: Gadiformes).] Invertebr. Zool. 7: 123-132. (In Russian with English abstract).

Stossich M. 1896: Ricerche elmintologiche. Boll. Soc. Adriat. Sci. Nat. Trieste 17: 121-136.

Wu H.S., Huang Z.X. 1964: [Notes on Philometra fujimotoi Furuyama, 1932 with the legend of its of relation to the developmental stage of Anguilla japonica.] Chin. J. Zool. 6: 86-87. (In Chinese.)
Yamaguchi Y., Sakaguchi S., Goto M. 1973: [Studies on a nematode, Philometra, in the marine benthis fishes - I. Distribution in the northwest areas of Hiroshima Bay morphological observations on the adult fluke.] Bull. Nansei Reg. Fish. Res. Lab. 6: 9-16. (In Japanese with English abstract.)

Yamaguti S. 1935: Studies on the helminth fauna of Japan. Part 9. Nematodes of fishes, 1. Jpn. J. Zool. 6: 337-386.

Yamaguti S. 1941: Studies on the helminth fauna of Japan. Part 33. Nematodes of fishes, II. Jpn. J. Zool. 9: 343-395 + Plts IV-VI.

Yamaguti S. 1961: Studies on the helminth fauna of Japan. Part 57. Nematodes of fishes, III. J. Helminthol., R.T. Leiper Suppl., pp. 217-228.

Yorke W., Maplestone P.A. 1926: The Nematode Parasites of Vertebrates. J. \& A. Churchill, London, 536 pp.

Cite this article as: Moravec F., Nagasawa K., Nitta M., Tawa A. 2019: New records of philometrids (Nematoda: Philometridae) from marine fishes off Japan, including description of Philometra kidakoi sp. $\mathrm{n}$. and Congerinema japonicum gen. et sp. $\mathrm{n}$. Folia Parasitol. 66: 021. 